LAWRENCE LIVERMORE N A T IO N A L LABORATORY

Use of Data Denial Experiments to Evaluate ESA Forecast Sensitivity Patterns

J. Zack, E. J. Natenberg, G. V. Knowe, J. Manobianco, K. Waight, D. Hanley, C. Kamath

September 14, 2011 
This document was prepared as an account of work sponsored by an agency of the United States government. Neither the United States government nor Lawrence Livermore National Security, LLC, nor any of their employees makes any warranty, expressed or implied, or assumes any legal liability or responsibility for the accuracy, completeness, or usefulness of any information, apparatus, product, or process disclosed, or represents that its use would not infringe privately owned rights. Reference herein to any specific commercial product, process, or service by trade name, trademark, manufacturer, or otherwise does not necessarily constitute or imply its endorsement, recommendation, or favoring by the United States government or Lawrence Livermore National Security, LLC. The views and opinions of authors expressed herein do not necessarily state or reflect those of the United States government or Lawrence Livermore National Security, LLC, and shall not be used for advertising or product endorsement purposes.

This work performed under the auspices of the U.S. Department of Energy by Lawrence Livermore National Laboratory under Contract DE-AC52-07NA27344. 


\title{
Use of Data Denial Experiments to Evaluate ESA Forecast Sensitivity Patterns
}

\author{
John Zack, Eddie Natenberg, Glenn Van Knowe, \\ John Manobianco, Ken Waight and Deborah Hanley \\ AWS Truepower, LLC
}

Chandrika Kamath

Lawrence Livermore National Laboratory

6 September 2011 


\section{Introduction}

The overall goal of this multi-phased research project known as WindSENSE is to develop an observation system deployment strategy that would improve wind power generation forecasts. The objective of the deployment strategy is to produce the maximum benefit for 1- to 6-hour ahead forecasts of wind speed at hub-height $(\sim 80 \mathrm{~m})$. In this phase of the project the focus is on the Mid-Columbia Basin region which encompasses the Bonneville Power Administration (BPA) wind generation area shown in Figure 1 that includes Klondike, Stateline, and Hopkins Ridge wind plants.

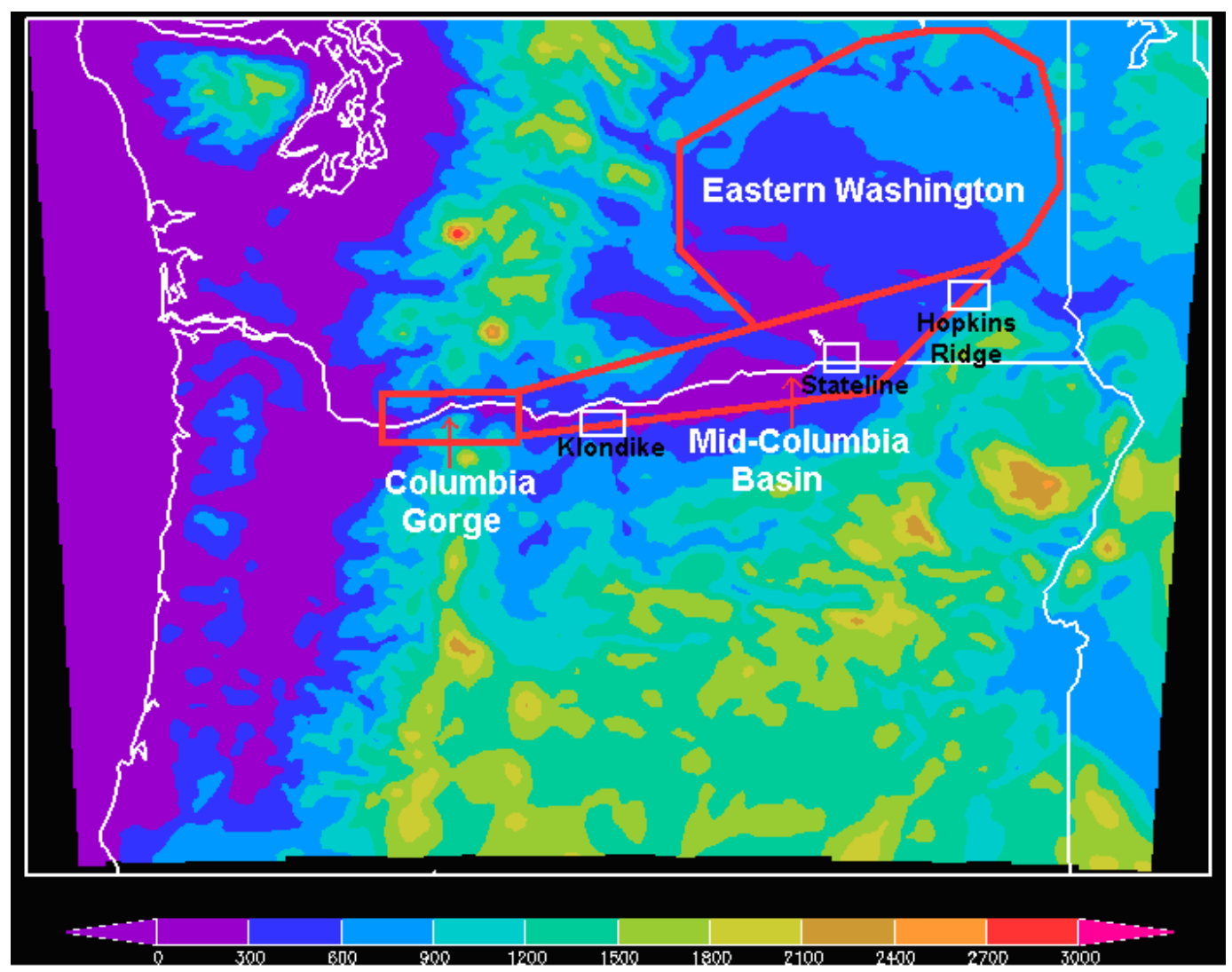

Figure 1. Geographical area used in the ensemble sensitivity analysis experiments. A matrix of 199 by 199 horizontal points with a spacing of approximately $4 \mathrm{~km}$ between points was overlaid on the Washington-Oregon domain for the experiments. The color shading depicts the terrain elevation $(m)$ on the scale of the model grid. The white boxes denote the forecast target areas for which the forecast metric (80-m wind speed) was calculated.

The Ensemble Sensitivity Analysis (ESA) approach uses data generated by a set (ensemble) of perturbed numerical weather prediction (NWP) simulations for a sample time period to statistically diagnose the sensitivity of a specified forecast variable (metric) for a target location to parameters at other locations and prior times referred to as the initial condition (IC) or state 
variables. The ESA approach was tested on the large-scale atmospheric prediction problem by Ancell and Hakim 2007 and Torn and Hakim 2008. ESA was adapted and applied at the mesoscale by Zack et al. (2010a, b, and c) to the Tehachapi Pass, CA (warm and cools seasons) and Mid-Colombia Basin (warm season only) wind generation regions.

In order to apply the ESA approach at the resolution needed at the mesoscale, Zack et al. (2010a, $\mathrm{b}$, and c) developed the Multiple Observation Optimization Algorithm (MOOA). MOOA uses a multivariate regression on a few select IC parameters at one location to determine the incremental improvement of measuring multiple variables (representative of the IC parameters) at various locations. MOOA also determines how much information from each IC parameter contributes to the change in the metric variable at the target location. The Zack et al. studies (2010a, b, and c), demonstrated that forecast sensitivity can be characterized by well-defined, localized patterns for a number of IC variables such as 80 -m wind speed and vertical temperature difference.

Ideally, the data assimilation scheme used in the experiments would have been based upon an ensemble Kalman filter (EnKF) that was similar to the ESA method used to diagnose the MidColombia Basin sensitivity patterns in the previous studies. However, the use of an EnKF system at high resolution is impractical because of the very high computational cost. Thus, it was decided to use the three-dimensional variational analysis data assimilation that is less computationally intensive and more economically practical for generating operational forecasts.

There are two tasks in the current project effort designed to validate the ESA observational system deployment approach in order to move closer to the overall goal:

(1) Perform an Observing System Experiment (OSE) using a data denial approach which is the focus of this task and report.

(2) Conduct a set of Observing System Simulation Experiments (OSSE) for the MidColombia basin region. The results of this task are presented in a separate report.

The objective of the OSE task involves validating the ESA-MOOA results from the previous sensitivity studies for the Mid-Columbia Basin by testing the impact of existing meteorological tower measurements on the 0 - to 6 -hour ahead $80-\mathrm{m}$ wind forecasts at the target locations. The testing of the ESA-MOOA method used a combination of data assimilation techniques and data denial experiments to accomplish the task objective.

\section{Methods and Configuration}

This section describes the configurations and methods used for analysis, data assimilation, and modeling.

\subsection{ARPS Model}

The Advanced Regional Prediction System (ARPS; Xue et al. 2000, Xue et al. 2001), version 5.2.11, was used employing for the simulations in this study. The model domain (shown in 
Figure 1) included $199 \times 199 \times 35$ points with a horizontal grid spacing of $4 \mathrm{~km}$. The average vertical spacing between levels was $500 \mathrm{~m}$ with higher resolution in the boundary layer to better resolve turbine-level winds. The grid was centered in the Mid-Columbia Basin at $45.56 \mathrm{~N}$ latitude and $120.98 \mathrm{~W}$ longitude.

The ARPS model was configured to use a 6 seconds long and 3 seconds short time step to ensure the numerical stability. No convective parameterization was used. A 1.5 order turbulence kinetic energy (TKE) scheme was used to calculate the mean kinetic energy per unit mass associated with eddies in turbulent flow. Simplified surface radiation physics, a forth order advection scheme, and the Lin (et al. 1983) ice microphysics scheme were also used.

Twenty four hour forecasts were executed twice a day at 0000 UTC and 1200 UTC for 44 days during the warm (1 May - 20 June 2007) and 51 days during the cool (1 January - 20 February 2010) season.

\subsection{Description and Configuration of ESA and EnKF Methods}

ESA and the ensemble Kalman filter (EnKF) were the key methods used to evaluate forecast sensitivity in this study. These methods rely on a sample of ensemble members to determine the correlation of perturbed initial state variables and impact on the target location metric variable. The ESA approach uses data generated by a set (ensemble) of perturbed NWP simulations for a sample time period to diagnose the sensitivity of a specified forecast variable (metric) for a target location to initial condition (IC) state variable(s) at other locations and prior times.

Ideally, the data assimilation scheme used in the experiments would have been based upon an ensemble Kalman filter (EnKF). EnKF would have been more consistent with the Mid-Colombia Basin sensitivity patterns diagnosed using ESA in the previous studies. However, the use of an EnKF system at high resolution is impractical because of the very high computational cost. Thus, it was decided to test the impact of assimilating observations using an economically practical data assimilation system (described in Section 2.4.1) that could be used to generate operational forecasts. For example, the three-dimensional variational analysis data assimilation method used in the forecast experiments required a total of 4,608 computer processing units (CPU) hours per each approximately 45 day experiment period as compared to the estimated 221,184 hours an EnKF data assimilation system would have used for the same period. To use an EnKF at 4-km horizontal resolution for making a single one day real time operational forecast for the MidColumbia Basin region would take 9,216 CPU hours, making it impractical for operational use.

The forecast metric (F) was defined as the average wind speed 80-m above ground level (AGL) over the target areas shown in Figure 1. The forecast sensitivity calculation is not restricted to the same variable used to define the forecast metric. Sensitivity values were calculated and evaluated for the thirteen IC state variables listed in Table 1 which includes the average $80-\mathrm{m}$ wind speed AGL. The IC state variables can be grouped into three categories: (1) Single level sensitivities, which include wind speed at various levels and 2-m temperature, (2) vertical wind shear, and (3) vertical temperature gradient. The wind shear and temperature gradient were computed for various layers from near the surface to a level of 2-km AGL (Zack et al. 2010a, b and c). 
Table 1. Thirteen IC state variables used in the evaluation of forecast sensitivity.

\begin{tabular}{|l|}
\hline \multicolumn{1}{|c|}{ Wind Speed Related } \\
\hline 80-m AGL wind speed \\
\hline 250-m AGL wind speed \\
\hline 1.5-km above mean sea level (AMSL) wind speed \\
\hline 3-km AMSL wind speed \\
\hline \multicolumn{1}{|c|}{ Wind Shear Related } \\
\hline 10-m to 80-m AGL wind shear \\
\hline 80-m to 500-m AGL wind shear \\
\hline 500-m to 1-km AGL wind shear \\
\hline \multicolumn{1}{|c|}{ Temperature Related } \\
\hline 2-m AGL temperature \\
\hline 2-m to 80-m AGL temperature difference \\
\hline 80-m to 1-km AGL temperature difference \\
\hline 80-m to 500-m AGL temperature difference \\
\hline 500-m to 1-km AGL temperature difference \\
\hline 1-km to 2-km AGL temperature difference \\
\hline
\end{tabular}

The ensemble of NWP simulations is produced by starting with a single initial state at the beginning of the analysis period and introducing statistical perturbations into the initial and lateral boundary conditions. For subsequent simulations, the initial state is a combination of the predicted and observed state. This process generates a set of simulations that differ from each other due to the perturbations. The number of simulations must be large enough to produce a statistically significant sample for the sensitivity calculations. Zack et al. (2010 a, b, and c) and other past studies (Torn and Hakim 2008) have used 48 or more ensemble members for largescale ESA applications

The evaluation of simulation "spread" or differences between individual members of the ensemble was accomplished using EnKF (Houtekamer and Mitchell 1998; Evensen 2007). The EnKF attempts to balance the predicted and observed state of the atmosphere by estimating the likelihood of each state at any given time over the entire set of simulations in the ensemble. The EnKF assumes that model errors follow a normal Gaussian distribution in order to determine the most probable state of the atmosphere. 
The forecast error was assessed using the time-dependent spread and deviations obtained from the ensemble state with that of the observed state. Ensemble members were allowed to integrate forward in time while the EnKF monitored the spread in the ensemble. The EnKF assessed predictabilities (likelihood of occurrence) of the variable of interest for the target area by monitoring the change in the spread of the NWP ensemble.

\subsection{MOOA}

The MOOA is a standard multivariate regression using a few select IC parameters at one location. The goal of using this method was to determine the incremental improvement of measuring multiple variables (representative of the IC parameters) at various locations and how much information from each IC parameter contributed to the change in the metric variable at the target location.

The MOOA determined the significance of each variable observed at several locations of interest. It is also able to help determine the incremental improvement in the forecast in that, given one observation, it could help determine how much value there is in adding a second observation of a different parameter at the same location. It is important not to assimilate redundant information into the model state when there is little value in adding a second observation. Three variables that showed high average coefficient of determination $\left(\mathrm{R}^{2}\right)$ for average sensitivity values during the 47 -day analysis period from previous research by Zack et al. (2010 a, b, and c) were chosen for the MOOA analysis at the location of the highest average $\mathrm{R}^{2}$ value. The IC variables were: $80-\mathrm{m}$ wind speed, $10-\mathrm{m}$ to $80-\mathrm{m}$ wind shear and $2-\mathrm{m}$ to $80-\mathrm{m}$ temperature gradient.

\subsection{Data Assimilation Methods and Configuration}

There were two assimilation systems used in the experiments: (1) a three-dimensional variational analysis scheme (ARPS 3DVAR) and (2) the Bratseth (1986) ARPS Data Assimilation System (ADAS) analysis scheme. An experiment using an incremental update analysis (IAU) scheme in ARPS was also used in conjunction with the 3DVAR assimilation system. Table 2 provides a comparison of the pros and cons of the data assimilation schemes used.

Table 2. Comparison of the pros and cons of the data assimilation schemes used

\begin{tabular}{|l|l|l|}
\hline Method & Pro & Con \\
\hline 3DVAR & $\begin{array}{l}\text { Can add information in areas where no } \\
\text { observations are taken using constraints } \\
\text { and gradient solutions }\end{array}$ & $\begin{array}{l}\text { Can over fit the observation and can have } \\
\text { unrealistic estimates where observations are } \\
\text { not taken }\end{array}$ \\
\hline ADAS & $\begin{array}{l}\text { Only the model state near the } \\
\text { observation location is impacted }\end{array}$ & $\begin{array}{l}\text { Cannot estimate the model state in location } \\
\text { where observations are not taken, no room for } \\
\text { dynamic constraint }\end{array}$ \\
\hline $\begin{array}{l}\text { 3DVAR } \\
\text { IAupled with }\end{array}$ & $\begin{array}{l}\text { Can slowly bring in observations over a a } \\
\text { period of time to limit imbalances }\end{array}$ & $\begin{array}{l}\text { Observations may not be valid over a window } \\
\text { and may create imbalances if atmospheric } \\
\text { conditions change quickly over time }\end{array}$ \\
\hline
\end{tabular}


A brief description of the assimilation methods and how they were used in the experiment is given in the following sections.

\subsubsection{ARPS 3DVAR}

A three-dimensional variational analysis method was used for a majority of the experiments. The ARPS 3DVAR (Xue et al. 2003) package consists of a cost function in which the solution seeks the most likely balance between a background (first guess) state, measurements of the observed state of the atmosphere, and any defined dynamic constraints that can add continuity and balance to the final analysis state. Mathematically a "cost function" is designed to select the best solution from some set of numerical relationships. This solution is achieved by a weighted summation of several different terms, one which includes the influence of the background, one which includes the influence of the observations and a term that includes the dynamical constraints. When combined ideal balance and weighting is achieved when the summation of these terms produces the lowest possible value. In Equation 1, $\mathrm{x}$ is modified to produce the lowest value of $\mathrm{f}(\mathrm{x})$ at each grid point. The solution then becomes $x$ which achieves the lowest value of $f(x)$.

$$
f(x)=w_{1}\left(x-x_{1}\right)+w_{2}\left(x-x_{2}\right)+w_{3}\left(x-x_{3}\right)
$$

The ARPS 3DVAR package reads in observations and a first-guess model state, both with user defined estimated error values. The first-guess field or background state can come from an initial sounding or previous model forecast (as used in this project). The observed and background errors allow the software to estimate what sources of data are reliable and should be used to produce a final analysis state. The use of dynamic constraints (to introduce smoothing, adjust divergence, etc.) helps produce a balanced final analysis state. These terms in the cost function help reduce noise or large scale phase errors from being resolved in the analysis state.

The ARPS 3DVAR package solves the cost function using an iterative pass-by-pass approach. Each data source can be assimilated along with other observations that are on a similar representative length scale. For instance, upper air observations are usually representative of the atmospheric state over several hundred kilometers, while a surface level observation may only be representative over 10-50 $\mathrm{km}$ depending upon the observation density. The vertical and horizontal scales of influence or spatial distance at which the observation can impact the model state, are commonly decreased from the first to second and following passes. Information about the observational increment is spread to neighboring gridpoints through the use of a recursive filter and the user specified length scales. The dynamical constraints can also be applied on a pass-by-pass basis.

Meteorological tower observations were assimilated in one analysis pass without any additional data. Information from each observation was spread to neighboring gridpoints using four recursive filter passes using a length scale of $75 \mathrm{~km}$ in the horizontal and two grid points in the vertical. These length scales were chosen by performance several assimilation experiments to make sure observations only impacted areas located close to the observation location. Only a smoothing function was applied during all the assimilation runs except for the divergence constraint run in which the divergence function was also applied. For all experiments, the 
background state was obtained from the North American Mesoscale (NAM) model analysis.

\subsubsection{3-D Divergence Constraint}

Within the ARPS 3DVAR data assimilation package, there is an option to employ a 3-D divergence constraint. The 3-D divergence convergence constraint was applied to reduce model imbalances in first few hours. In meteorology, mass divergence or convergence is the condition characterized by the uniform expansion or contraction a parcel of air where mass is conserved. Mass divergence or convergence associated with the observed wind data can produce imbalances in the model in areas where observational information is missing. In the ARPS 3DVAR software, the amount of mass divergence or convergence function is controlled by a mass divergence constraint equation derived from the mass continuity equation that is imposed on the analyzed wind field (Gao et al. 1999, 2004). The amount of mass divergence allowed in the model is controlled by weighting coefficients in both the horizontal and vertical. The weighting terms were set to different values and experiments (not all shown in this report) were conducted to allow for the testing of the impact of divergence on the forecasted state, similar to $\mathrm{Hu}$ et al. (2006).

\subsubsection{Modified Observation Spatial Correlation}

As discussed in Section 2.4.1 (ARPS 3DVAR), the horizontal and vertical impact of an element of measurement data (e.g. 80-m wind speed and direction data from a site) is controlled by a user specified radius of influence that is representative of the atmospheric scales of the observations. This radius of influence determines to what spatial extent an observational value will impact neighboring grid points within the model state. A large radius of influence tends to spread information out farther distances, while smaller values limit the impact of the observation on the atmospheric state to the grid points close to the observation location. This information is spread evenly (i.e. isotropically) away from the observation location through the use of a recursive filter. The recursive filter determines the shape and spatial extent of the analysis increment (or observational impact). This is achieved by adding forward and subtracting a backward moving weighted function which is initialized using a previous value to the right (or left) of the grid point from the observation point. This function achieves the same effect as a painters brush, spreading a small amount of paint out radially with brush strokes away and towards the initial placement of paint.

Non-isotropic or anisotropic filters can estimate how the observational information impact the analysis state based on estimates of observation representativeness and distance away from the observation location. It is thought that for the Mid-Columbia region, observations should only impact the atmospheric state in locations parallel to the flow and locations of similar terrain to where the observation was taken.

Therefore, to estimate the impact of a non-isotropic filter, a pseudo-anisotropic filter was designed to determine its impact on the numerical analysis. The pseudo-anisotropic filter differs from a true anisotropic filter in that the aspect ratio was subjectively set by the user instead of being explicitly estimated by the assimilation system from information about the background state. The development of a pseudo-anisotropic filter avoided the need for the development of a 
complete anisotropic filter software package. The pseudo-anisotropic filter was developed by modifying the isotropic filter to include an aspect ratio in the direction perpendicular to the flow to limit observational impact to areas in the Columbia Basin where the terrain is more uniform and the general atmospheric flow is parallel.

\subsubsection{Incremental Analysis Update (IAU)}

A set of experiments using the Incremental Analysis Update (Bloom et al. 1996) method were conducted in an attempt to control imbalances that may be introduced into the model through the data assimilation process. The IAU scheme gradually introduces observational information into the model (using a weighting term) over a predetermined period of time to reduce imbalances. The process occurs after a numerical analysis is performed and the incremental change (analysis increment) from the background to the analysis state has been estimated. The IAU impact on the model state can be adjusted with a gain parameter. The gain allows for observations to have a larger impact when used during the beginning of a forecast or a pre-forecast spin-up period to avoid signal dampening of the analysis increment as the model advances.

\subsubsection{ADAS Assimilation Package}

A second assimilation package employed for this project was the ARPS Data Assimilation System (ADAS). This software package is based on the successive correction method (SCM) that converges to optimal interpolation following Bratseth (1986) and Brewster (1996) who applied the technique to mesoscale modeling. The method uses an iterative approach similar to that of 3DVAR with empirical weighting instead of a cost function. Observation influence is also controlled by a radius of influence which can impact the relative weights of the observations and background field without the use of a recursive filter. Therefore, ADAS can offer a solution that is independent of the techniques used in 3DVAR.

\subsubsection{Key Settings Used in Experiments}

The following settings were used for 3DVAR. All key parameters are summarized in Table 3.

1) One analysis pass to assimilate all available data, and then four filter passes per analysis pass to develop the isotropic spatial correlations.

2) A $75-\mathrm{km}$ radius of influence in all but the modified correlation experiment. This radius was chosen based on the performance of several sensitivity experiments for selected cases.

3) A $37.5-\mathrm{km}$ north to south influence was used in the modified (pseudo-anisotropic) correlation experiment.

4) The divergence weighting coefficients were set to zero effectively imposing no divergence constraint in all but the divergent constraint experiments. In the divergence constraint experiments, both the vertical and horizontal weighting term were set to 0.001. For the ADAS experiment that did not use the 3DVAR settings, the default settings were used.

As noted earlier, for all experiments in this study the background state was obtained from the 
North American Mesoscale (NAM) model.

Table 3. Settings used for the 3DVAR assimilation runs.

\begin{tabular}{|l|c|}
\hline \multicolumn{1}{|c|}{ 3DVAR Parameter } & Setting \\
\hline Number of Analysis Passes & 1 \\
\hline Data type used on pass & Met Towers \\
\hline Number of maximum cost function iterations & 50 \\
\hline Number of recursive filter passes & 4 \\
\hline Horizontal Length Scale & $75 \mathrm{~km}$ \\
\hline $\begin{array}{l}\text { East to West Horizontal Length Scale modified } \\
\text { correlation experiment }\end{array}$ & $37.5 \mathrm{~km}$ \\
\hline *Vertical Length Scale & 2 grid points \\
\hline $\begin{array}{l}\text { Horizontal divergence constraint weighting for } \\
\text { divergence constraint experiment }\end{array}$ & 0.001 \\
\hline $\begin{array}{l}\text { Vertical divergence constraint weighting for } \\
\text { divergence constraint experiment }\end{array}$ & 0.001 \\
\hline Smoothing constraint weighting & 0.05 \\
\hline
\end{tabular}

* For 80-m tower observations, below 80 meters the spacing between two grid points is in the range of 50 meters and above 80 meters the spacing is in the range of 100 meters.

\subsection{Descriptions of Data Denial and Data Assimilation Experiments}

The following sections describe the data used and how the data assimilation was done for each simulation experiment.

\subsubsection{Data Used}

Observed data from six meteorological (met) towers in locations showing varying degrees of sensitivity as determined from the ESA results were used for both the warm and cool season simulation experiments. The met tower sites selected were Seven-Mile-Hill, Chinook, Vansycle, Goodnoe Hills, Wasco, and Kennewick (Table 4). The number of levels and heights varied for each met tower site and are summarized in Table 5. When comparing the network of assimilated observations to the ESA results, it was estimated that Goodnoe Hills had the lowest sensitivity and Chinook had the highest sensitivity to $80-\mathrm{m}$ wind speed at the three target locations. The warm season forecasts were verified using tower data located on-site at the wind farms Hopkins Ridge, Stateline, and Klondike (1 and 2). Table 6 lists the forecast target locations met towers and observation heights for both seasons. BPA was the source for all met tower data.

For verification of the cool season simulation experiments, data were unavailable from the onsite towers at the target locations. Therefore, proxy off-site met towers were used for verification during the cool season including Hood River (for Klondike), Horse Heaven (for Stateline) and Roosevelt. Roosevelt is between Klondike and Stateline. In addition, Wasco and Vansycle met towers, which had data available for the entire period, were used for cool season verification. Wasco was a proxy for the Klondike location and Vansycle was a proxy for the Stateline 
location. There was not a reasonable proxy for Hopkins Ridge. The target locations and sites of towers used for assimilation and verification are summarized in Table 7 with locations provided in Figure 2.

Table 4. Overview list of assimilated data sites, forecast targets and verification sites.

\begin{tabular}{|c|c|c|}
\hline $\begin{array}{l}\text { Assimilated Data Sites } \\
\text { (Met Towers) for Warm } \\
\text { and Cool Seasons }\end{array}$ & $\begin{array}{l}\text { Forecast Target Sites } \\
\text { (Warm and Cool Season) } \\
\text { On-site Met Tower } \\
\text { Verification Sites for } \\
\text { Warm Season Only }\end{array}$ & $\begin{array}{l}\text { Off-site Met Tower Verification } \\
\text { Sites for Cool Season Only }\end{array}$ \\
\hline $\begin{array}{l}\text { SHM: Seven Mile Hill } \\
\text { CNM: Chinook } \\
\text { VNM: Vansycle } \\
\text { GHM: Goodnoe Hills } \\
\text { WOM: Wasco } \\
\text { KZM: Kennewick }\end{array}$ & $\begin{array}{l}\text { HKM: Hopkins Ridge } \\
\text { SLM: Stateline } \\
\text { K1M: Klondike } 1 \\
\text { K2M: Klondike } 2\end{array}$ & $\begin{array}{l}\text { HHM: Horse Heaven (SLM proxy) } \\
\text { HRM: Hood River (KM* proxy) } \\
\text { RSM: Roosevelt (SLM/KM* proxy) } \\
\text { WOM: Wasco (KM* proxy) } \\
\text { VNM: Vansycle (SLM proxy) }\end{array}$ \\
\hline
\end{tabular}

$\mathrm{KM}^{*}$ represents both Klondike $1(\mathrm{~K} 1 \mathrm{M})$ and Klondike 2 (K2M)

Table 5. List of assimilated data sites and observation heights for both warm and cool seasons.

\begin{tabular}{|l|l|}
\hline \multicolumn{1}{|c|}{ Assimilated Data Sites (Met Towers) } & \multicolumn{1}{c|}{ Observation Heights (m)AGL) } \\
\hline SHM: Seven Mile Hill & 15.230 .4 \\
\hline CNM: Chinook & 49.9 \\
\hline VNM: Vansycle & $29.8,30.8,44.5,61.3,62.5$ \\
\hline GHM: Goodnoe Hills & $15.24,30.48$ \\
\hline WOM: Wasco & 30.48 \\
\hline KZM: Kennewick & 26.213 \\
\hline
\end{tabular}

Table 6. List of forecast target locations met towers and observation heights for both seasons. These on-site met towers were used only for warm season forecast verification.

\begin{tabular}{|l|c|}
\hline Target Locations (On-Site Met Towers) & Observation Heights (m AGL) \\
\hline HKM: Hopkins Ridge & 80.0 \\
\hline SLM: Stateline & 80.0 \\
\hline K1M: Klondike 1 & 80.0 \\
\hline K2M: Klondike 2 & 80.0 \\
\hline
\end{tabular}


Table 7. List of proxy off-site met tower sites and observation heights used as cold season verification location. Also listed is the target location associated with each proxy site.

\begin{tabular}{|l|c|l|}
\hline Off-Site Met Towers & $\begin{array}{c}\text { Observation Heights } \\
\text { (m AGL) }\end{array}$ & Representative Target Location \\
\hline HHM: Horse Heaven & 21.3 & SLM \\
\hline HRM: Hood River & 9.1 & KM$^{*}$ \\
\hline RSM: Roosevelt & 21.3 & SLM/KM* \\
\hline WOM: Wasco & 30.5 & $\mathrm{KM}^{*}$ \\
\hline VNM: Vansycle & 62.5 & SLM \\
\hline
\end{tabular}

$\mathrm{KM}^{*}$ represents both Klondike $1(\mathrm{~K} 1 \mathrm{M})$ and Klondike $2(\mathrm{~K} 2 \mathrm{M})$

Before data assimilation, the met tower data were analyzed for significant errors, such as negative values of wind speed, and converted from local to UTC time. The temperature, wind direction, and wind speed were then assimilated using ARPS 3DVAR or ADAS at observation heights. Additional quality control methods were applied such as buddy checking observational data with neighboring grid points and gradients.

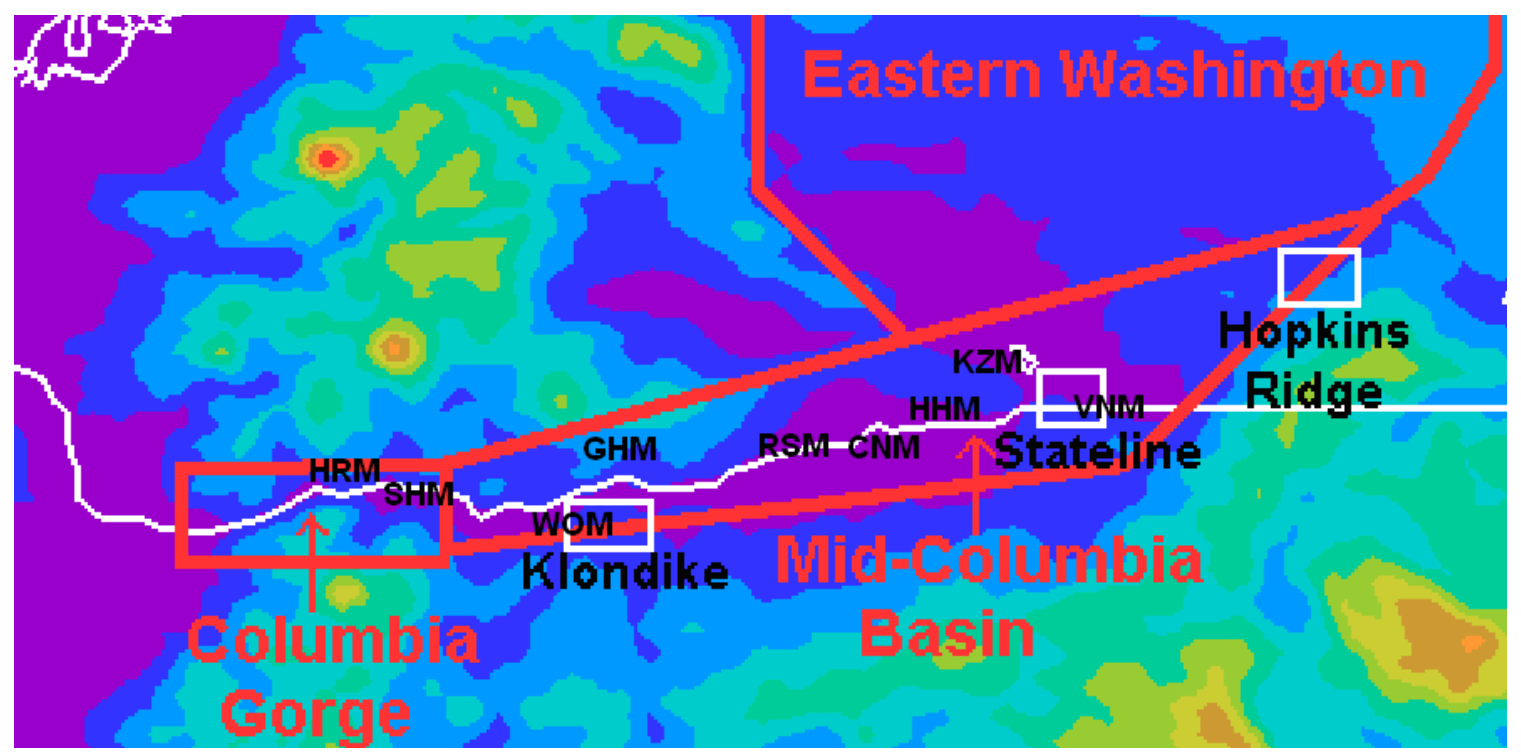

Figure 2. Location of assimilated and verification met towers. Met towers from generally west to east are Hood River (HRM), Seven Mile Hill (SHM), Wasco (WOM), Goodnoe Hills (GHM), Roosevelt (RSM), Chinook (CNM), Horse Heaven (HHM), Kennewick (KZM), and Vansycle (VNM).

\subsubsection{Data Denial and Data Assimilation Experiments}

A total of eight types of simulation experiments were run for the warm season and four types for the cool season. Experiments for the warm season of 2007 were performed in the following sequence:

1) Control Run: The control run did not assimilate any met tower data. No numerical 
analysis was performed.

2) All Assimilation Run: The observed data from all six met towers were assimilated for this experiment. The reason for the experiment was to determine a baseline impact of assimilated data from the entire met tower network during the warm season.

3) High Sensitivity Run: Only observed data from the Chinook met tower, which is in a highly sensitive location as determined by ESA, was assimilated for this experiment. The reason for the experiment was to determine if an ESA-identified high sensitivity location would contribute information to the initial state improving forecast performance.

4) Low Sensitivity Run: Only observed data from the Goodnoe Hills met tower, which is in a low sensitive location as determined by ESA, was assimilated for this experiment. This experiment was run to determine if a low sensitivity location would have little impact on forecast performance as predicted by the ESA method.

5) Divergence Constraint Run: An additional experiment was run to assimilate the same six met towers used in the 'All Assimilation Run'. A divergence constraint was included to adjust the initial mass field so it would be more dynamically in balance. This experiment was run in an attempt to decrease the impact of possible dynamical imbalances in the first few hours of the model run.

6) Modified Spatial Correlation Run: For this experiment, all six observed met tower sites were assimilated. The aspect ratio of the recursive filter was manually adjusted to create an anisotropic spatial correlation which may better represent background error. In this way, it could be determined if a forecast is sensitive to the covariance structure (shape) as subjectively estimated by regional flow. If there is a correlation between the forecast performance and covariance filter type, a more sophisticated assimilation system may be required to assess the value of the ESA results.

7) IAU Run: An additional experiment was performed using IAU with a 5\% gain and 15 minute period of adjustment. The objective of this experiment was to determine if IAU could reduce imbalances in the initial state by allowing the model to adjust more gradually to the analysis increments while slowly advancing forward in time.

8) ADAS Run: An experiment was performed using standard ADAS Bratseth data assimilation instead of the 3DVAR technique. This run was performed to determine the impact of the met tower data on a forecast without using a 3DVAR cost function.

After running the first four warm season experiments (experiments 1 - 4 above), it became apparent that model imbalances that develop during the forecast after assimilating observations in the initial state were causing increased forecast error. Therefore, an additional four warm season experiments ( $5-8$ above) were developed and run to test the impact of data assimilation on the forecast error. The 3DVAR data assimilation technique was used for all but the ADAS experiment. 
Four experiments were performed for the 2010 cool season in the following sequence:

1) Control Run: The control run did not assimilate any data. No numerical analysis was performed.

2) All Assimilation Run: The observed data from all six met towers were assimilated for this experiment to determine the baseline impact of the entire tower network during the cool season.

3) High Sensitivity Run: Only observed data from the Chinook met tower, which is in a highly sensitive location as determined by ESA (warm season analysis, as only warm season was done previously) was assimilated for this experiment. The reason for this experiment was to determine if a high sensitivity location could contribute information to the initial state that would positively impact forecast performance during the cool season.

4) Low Sensitivity Run: Only observed data from the Goodnoe Hills met tower, which was in a low sensitive location, were assimilated for this experiment. This experiment was run to determine if a low sensitivity location would have little impact on forecast performance as predicted by the ESA method.

The cool season experiments 1 - 4 did not exhibit the same initialization problems as the warm season runs. Additional time was spent exploring data assimilation techniques that have the potential to improve the initialization and forecast for the warm season. Therefore, due to the time constraints of the project, the warm season data assimilation technique experiments $5-8$ were not accomplished for the cool season. Once significant improvement is made in initializing the model for the warm season, the technique could then be further tested by performing additional cool season experiments.

\subsubsection{Verification Methods}

Verification for the 2007 warm season period was performed using the $80-\mathrm{m}$ wind speed AGL as the metric variable at the target locations of Hopkins Ridge, Stateline, and Klondike 1 and 2. The forecast sensitivity pattern (based on the average $R^{2}$ ) of the $80-m$ wind speed was fairly consistent for all three target locations during the warm season. Figure 3 shows an example of the similarity between the average $\mathrm{R}^{2}$ of the 3 -hour sensitivity regression for 80 - $\mathrm{m}$ wind speed at Stateline and Hopkins Ridge. Therefore, warm season results from Stateline are shown in section 4 as representative of other target locations. 


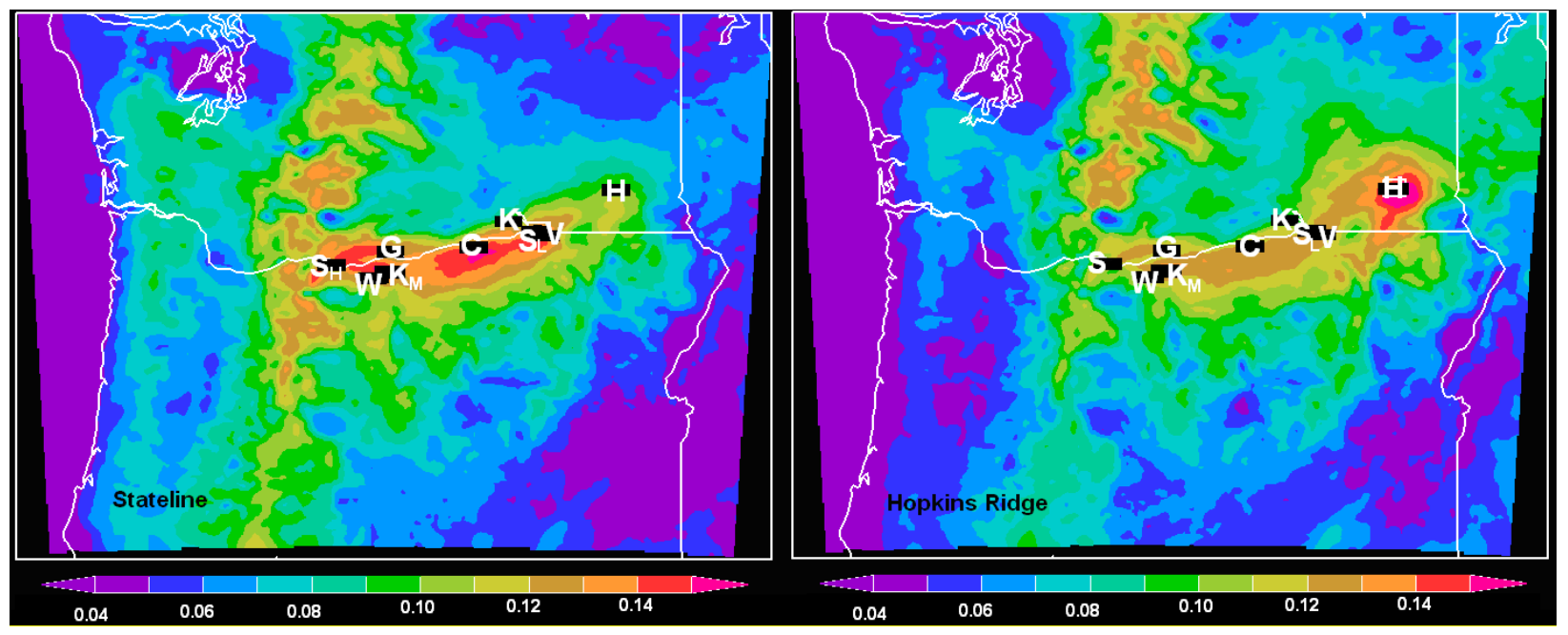

Figure 3. The three-hour average $R^{2}$ of the sensitivity plots of 80 meter wind speed for Stateline (left) and Hopkins Ridge (right) showing similar sensitivity patterns. Both plots show an area of elevated $R^{2}$ values that follow the Columbia River Basin from west to east, denoted by the orange (>0.12) shading along the Oregon Washington border. . Locations from generally west to east are, Seven Mile Hill ( $\left.S_{H}\right)$, Wasco (W), Goodnoe Hills (G), Klondike (KM), Chinook (C),) Kennewick (K),Stateline $\left(S_{L}\right)$, Vansycle (V) and Hopkins Ridge $(H)$.

For both the warm and cool season, verification was performed every half hour up to six hours and every hour after six hours until the end of the 24-hour verification period. The verification software reads in observations at 10 minute intervals and computes the difference between the observation and model state at the observation location. The verification software was configured to compute the mean absolute error (MAE), root mean squared error (RMSE), and bias for wind speed at the observation height over the entire verification period.

For the warm season, the sample included 44 days with a forecast initialized twice per day which yielded a total of 88 forecasts. The warm season sample consisted of fewer days than the ESA period due to several days of missing initial condition data. For the cool season, the sample included 51 days with forecasts initialized twice each day for a total of 102 forecasts.

The verification period for the 2010 cool season period extended from 1 January 2010 at 0000 UTC to 20 February 2010 at 1200 UTC. Verification was employed several sources of data including observed wind speed at two previously assimilated tower locations, Vansycle and Wasco. For these sites, the observation height closest to the $80-\mathrm{m}$ level was used. A second source came from a new network of meteorological towers which became available starting 1 February 2010. The new met towers provided observations between 10- and 30-m. The three new met towers used for verification were Horse Heaven, Hood River, and Roosevelt. Horse Heaven is closest to Stateline, Hood River is closest to Klondike (1 and 2), and Roosevelt is in between both, but Roosevelt may have representativeness problems due to surrounding structures.

For verification of the cool season simulation experiments, data from the on-site target towers 
were unavailable, therefore the five met tower locations were used as proxies for the target locations for the period. There was not a reasonable proxy for Hopkins Ridge. Because data were unavailable for January 2010, the verification from the second source of off-site met tower data only includes February 2010. Although verification for all six assimilated towers and three new met towers were computed, the results of only a subset of towers are shown in this report (see Table 6).

\section{Factors Impacting Results}

The assimilation of representative observational data into the model is important to establish an accurate initial state for the forecast simulations. There were several significant factors that impacted the representativeness of the observational data. The factors can be divided into two categories:

(1) Factors related to observations:

- Unavailability of met tower data from sites representative of the target sites. This was a particular problem for the cool season time period.

- Observations at some locations may be greatly influence by small-scale terrain flows making them unrepresentative of the general flow patterns of the region.

(2) Factors related to the modeling system and data assimilation:

- Model grid spacing needed to resolve highly localized terrain flows.

- Dynamic imbalances that occur after data is assimilated associated with the data assimilation scheme.

More details are provided on each of the factors impacting the experiments in sections 3.1 and 3 .

\subsection{Observational Factors}

Observational factors can impact the results because data are used to initialize the forecast model and verify model performance at key locations of interest. An important factor that impacts the results presented in this study is a lack of observational data at key locations either for model assimilation or verification. Other factors include data quality and representativeness of the observations of the atmospheric conditions for the surrounding region. Data quality issues are defined as significant when they either can be either numerically or subjectively determined to be inaccurate. Examples of errors that are considered significant include errors in the magnitude or units of wind direction, wind speed and temperature.

Representativeness errors can occur due to poor siting and/or lack of sensor calibration. These errors may result in an observational value at a given location being unrepresentative of conditions in the immediate region. In the Mid-Columbia Basin, regions of steeply sloping terrain and nearby obstructions can decrease (or increase) the observed wind speed to values lower (or greater) than that representative of the overall region. Such data when used either for assimilation or verification can bias the actual forecast or forecast verification to a magnitude similar of that to the observation representativeness errors. 


\subsection{Modeling System and Data Assimilation Factors}

In areas such as the Mid-Columbia Basin, small-scale terrain driven flows may not be properly resolved by a short-term forecast model but captured by observational sensors. These flows can have a negative impact on the forecast because the assimilated data are from observations of higher resolution flows than can be resolved by the model. The error caused by the unresolved flow can then lead to error in the forecasts when observations of unresolvable structures are assimilated. Several techniques have been proposed to counteract model bias during data assimilation. One technique developed by Janjić and Cohn (2006) specifically focuses on bias corrections due to unresolved scales using a Kalman filter correction technique. A second more general technique developed by Mass et al. (2008) directly makes corrections to observations while taking into account model bias for a number of different observed variables. These techniques highlight the need to assess model bias during the assimilation process to produce a more representative set of atmospheric initial conditions and lead to a more accurate forecast. While the prior technique is still under development, future projects could easily implement the latter more general technique proposed by Mass et al. (2008), in which bias correction are applied directly to the atmospheric observations.

Assimilation of even highly accurate observational data can lead to a decrease in forecast accuracy if the assimilation system is not properly tuned to estimate how information from the observations should correlate to simulated atmospheric conditions of nearby grid points. The distribution of observational information to neighboring grid points must be performed in a way such that the assimilation method only influences those areas where a high correlation with the observation site is actually present. If the model spreads observational information to areas where the observed flow is not correlated to the true atmospheric flow, the model may be thrown out of a dynamic balance.

A dynamic imbalance is usually denoted by a systematic forecast bias in the hours just after assimilation, as opposed to other model biases which may lead to a consistent forecast bias over all forecast hours. This is most prominent when verifying against a statistically significant sample size. This imbalance in the initial atmospheric state forces the model to adjust until a dynamically balanced atmospheric state is achieved. This adjustment period is referred to as the model "spin-up" period. For a model that is initialized from a numerical analysis instead of a previous forecast, a spin-up period is needed for the model to dynamically adjust to flows that can be resolvable based on the terrain and model resolution. This tends to occur within the first 0 to 3 hours of a model forecast run. This period of adjustment is usually denoted by relatively high forecast MAE and bias when compared to available observations.

The influence of the data assimilation system, especially on the 0 - to 3-hour forecasts, is a major concern for the experiments done as part of this project. Many techniques employed in this study have been developed to help the model adjust to observations slowly and to conform to known dynamical relationships in the atmosphere in order to reduce initial imbalances and the amount of model spin-up. 


\section{Results}

The results of this study indicate that imbalances in the initial model state resulting from the assimilation process must be controlled before the relationship between forecast performance and the location of assimilated met tower data can be addressed.

The results are presented in several sections. Section 4.1 (warm season) and Section 4.2 (cool season) discuss results from the data denial experiments that focus on forecast sensitivity to the number and location of the met towers. In Section 4.3, results from the warm season data assimilation method experiments are discussed.

\subsection{Warm Season 2007}

During the warm season period (1 May - 20 June 2007), the Mid-Colombia basin was dominated by warm southwesterly onshore flow across the region. The southwesterly onshore flow was channeled through the Mid-Columbia Basin as it moved eastward impacting the Klondike (1 and 2), Stateline and Hopkins Ridge wind farms. Smaller scale regional flows developed from terrain induced differential heating and forcing within the basin and surrounding region. These flows were smaller in spatial extent than the model grid spacing was capable of resolving and often resulted in model imbalances after data are assimilated. This result is consistent with the findings of Sharp and Mass (2002) who studied the Mid-Columbia basin region extensively with respect to model resolution and flow structure.

The sample of 24-hour forecasts is similar for each site; therefore, only results from Stateline (between the Klondike and Hopkins Ridge wind plants) are shown. Both the MAE and bias represent average forecast performance during the entire period and include verification from all available forecast runs produced during the period.

During the control run, which did not assimilate any met tower observations, the MAE of the 80$\mathrm{m}$ wind speed forecast at the Stateline location decreased from 2 to $1.6 \mathrm{~ms}^{-1}$ between 0.5 and 1 hour into the forecast (blue line, Figure 4). The decrease in MAE during the first hour is likely related to imbalances in the initial state that result in a "spin-up" period. The control run maintained an average MAE between 1.6 to $1.8 \mathrm{~ms}^{-1}$ for the first 12 forecast hours. After the 12hour point, the MAE varied between 1.7 and $2.1 \mathrm{~ms}^{-1}$ for the rest of the forecast period.

The forecasts made with all available met tower data had distinctly different 24-hour forecast MAEs than the control run (red-orange line, Figure 4). Directly after initialization, the model forecast error was much lower than the non-assimilation control run as seen by the 30 -minute MAE value. The forecast error rapidly increases to exceed that of the control run by the end of the first hour. The error continues to increase until the 1.5-hour point and then levels off for an hour. The MAE decreases after the 2.5-hour point, converges with the control run MAE between the third and fourth hour, and has a similar MAE for most of the remaining 24 hours of the forecast. 


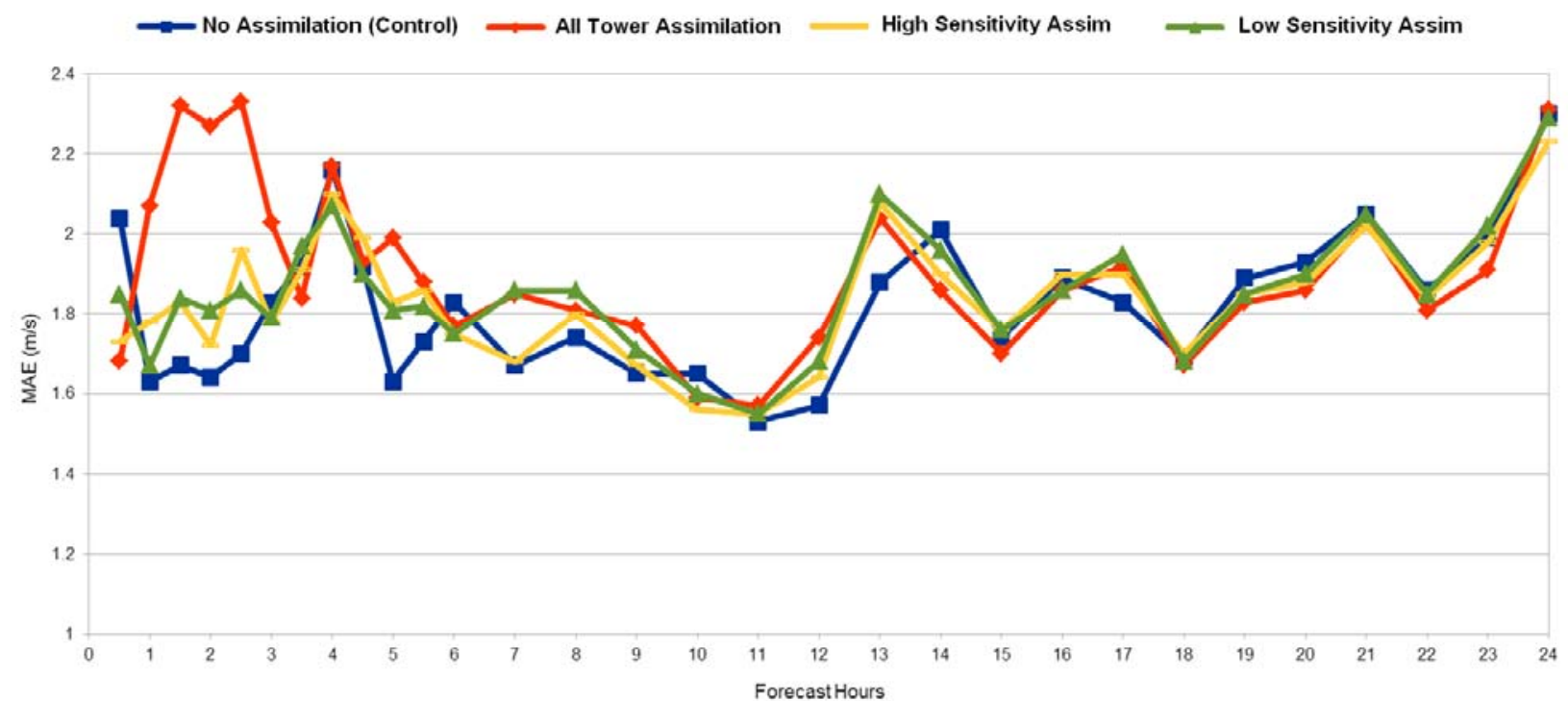

Figure 4. Mean absolute error (MAE) as a function of look-ahead time for twice per day (0000 and 1200 UTC initialization times) NWP forecasts of $80-\mathrm{m}$ wind speed $\left(\mathrm{ms}^{-1}\right)$ for the SLM (Stateline) wind farm for the warm season (1 May - 20 June 2007) for the control run without met tower data assimilation (blue line), the all six Bonneville Power Administration (BPA) meteorological tower data assimilation run (red-orange line), assimilation of a high sensitivity observation point (yellow line), and the assimilation of a low sensitivity observation point (green line).

The comparison of the control with the all-met tower data assimilation run indicates that the assimilation of the met tower data had two noteworthy impacts on the warm season's forecasts: (1) adding met tower observations significantly improves the initial state at the verification site and 1-hour forecast performance and (2) imbalances introduced into the model state cause an increase in forecast error during the spin-up period 1 to 3 hours into the forecast.

The impact of assimilating a single meteorological tower observation from a high or a low sensitivity location (selected using the ESA results) 3 hours prior to the forecasts time was also examined. The MAE for the high and low sensitivity location experiments are denoted by the green line for low sensitivity and yellow line for high sensitivity in Figures 4 and 5. In general, the forecast MAE out to 30 minutes are improved compared to the control by assimilating both the high and low sensitively points.

The MAE for the 0 - to 45-minute forecast using data from the high sensitivity met tower was lower than the less sensitive met tower. This result suggests that, during the first hour of the forecast, high sensitivity observations contribute more value in decreasing forecast error than the low sensitivity observations. Also, if dynamical imbalances in the initial model state are masking the impact of assimilating observations into the initial state on forecast performance for the 1 to 3 hour time frame, then there is potential to increase forecast performance if these imbalances can be minimized. Another important finding was that assimilating met tower data from just one highly sensitive point (yellow line) gave an initial verifications site state about a good as the all available met tower observations (red-orange line) but also provided forecasts with error within 
about $0.1 \mathrm{~ms}^{-1}$ of the control forecasts from the 45 minute to 3 hours forecast period.

For the 1- to 3-hour forecast period, the control simulations without data assimilation (blue line) were generally more accurate than any forecast with data assimilation. All forecasts performed similarly from hour 4 through the end of the forecast period. An analysis of these results suggests that the assimilated data, while increasing the accuracy of the 0- to 1-hour forecasts, also produced imbalances in the model leading to decreased accuracy for hours 1 to 3.

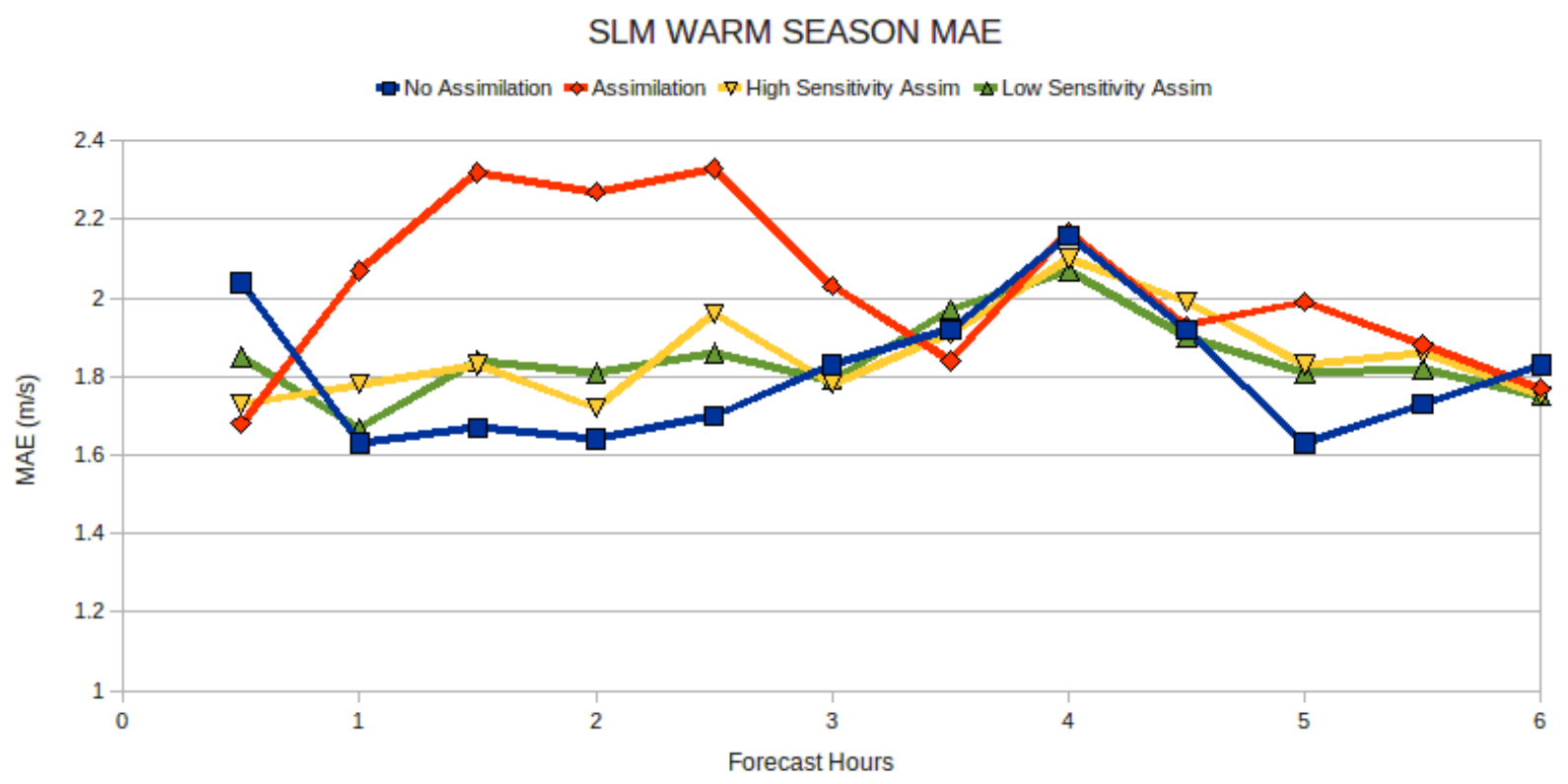

Figure 5. Same as Figure 4 except only shows first 6 hours of the forecast period.

The support for model imbalance caused by data assimilation impacting the forecast performance during spin-up can be further illustrated by examining model bias (Figure 6). The control run has the largest (negative) bias at the beginning of the forecast period while the all-met tower data assimilation run has its highest bias 1 to 2 hours into the forecast which would be consistent with model imbalances introduced by the assimilation of the observations. Additionally, for a single assimilated observation the error is greater than the control but less than the all-met tower data assimilation run indicating the magnitude of the dynamic imbalances increase with the number of assimilated observations.

To summarize, the assimilation of more observations helps produce a more accurate initial value of wind speed at the target location, but the dynamical imbalance overwhelms the model state and slowly diverges to a less accurate forecast than the control forecast within the first hour. The error of forecasts from runs with data assimilation of observations remains higher than the control between hours 1 and 3. Between 3 and 5 hours, the all-met tower data assimilation run converges to a forecast error value similar to that of the control run. As discussed in Section 3, there are many causes and proposed solutions to this problem associated with data assimilation. Section 4.3 discusses the results from additional experiments performed that used different data 
assimilation methods in an attempt to control the model imbalances caused by data assimilation.

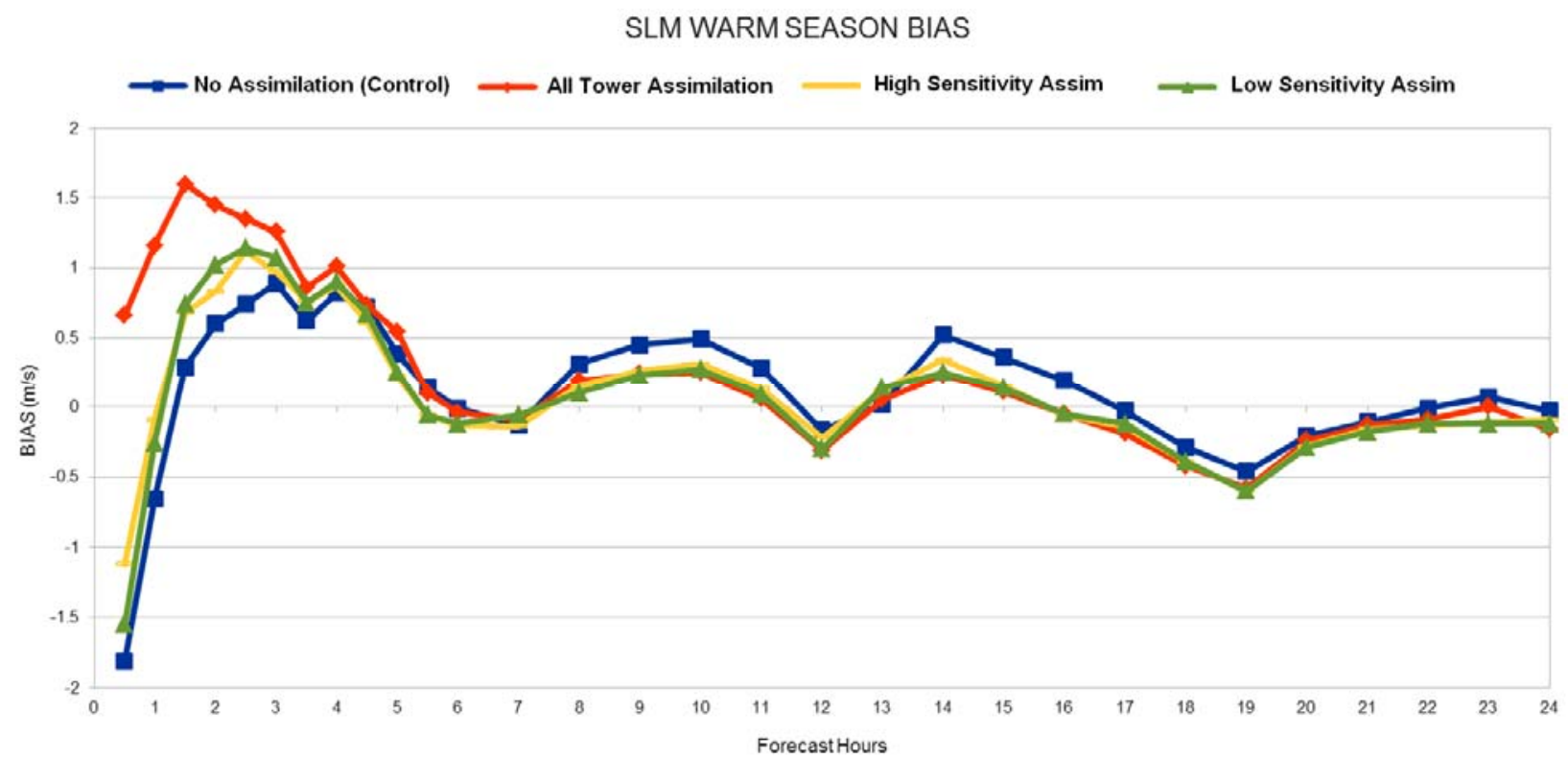

Figure 6. Bias (Mean Error) as a function of look-ahead time for twice per day (0000 and 1200 UTC initialization times) NWP forecasts of 80- $m$ wind speed $\left(\mathrm{ms}^{-1}\right)$ for the SLM (Stateline) wind farm for the warm season (1 May - 20 June 2007) for the control run without met tower data assimilation (blue line), the all six Bonneville Power Administration (BPA) meteorological tower data assimilation run (red-orange line), assimilation of a high sensitivity observation point (yellow line), and the assimilation of a low sensitivity observation point (green line).

The results from the four initial warm season experiments suggest the impact of assimilating the met towers observations tends to decrease the MAE during the first hour but leads to a dynamical adjustment period due to model imbalance within the second and third hour. The lower initial hour MAE was observed for all three experiments that assimilated the met tower observations. The lower initial hour MAE was most pronounced for the all and high sensitivity met tower assimilation experiments and less pronounced in the low sensitivity met tower assimilation experiment. The benefit of assimilating just one tower in the high and low sensitive assimilation experiments was due to the decreased magnitude of model imbalance and adjustment during hours 1 to 3 . During this period the MAE was only slightly higher than the control simulation and much lower than the all-met tower simulation.

The results were similar at both the Klondike and Hopkins Ridge target locations (not shown). Klondike, which is located further west and upstream from the met tower observations sites tended to have a slightly lower impact from the met tower observation assimilation than Stateline. The Hopkins Ridge target location tended to have a slightly higher impact from the assimilated observations because it is located downstream within the prevailing westerly basin flow. 


\subsection{Cool Season 2010}

The cool season period (1 January - 20 February 2010) results showed a much different impact from assimilating the met tower observations on forecast performance than what was observed in the warm season simulations. There are several factors influencing the cold season results that were not present for the warm season simulations:

(1) The general flow tends to be weaker, more southerly and more variable in the cool season than during the warm season. Also, the diurnally induced differential terrain heating is reduced, thereby decreasing the strength of localized circulations. The net result of the large and local scale cool season flow interaction is an overall weaker flow within the MidColumbia Basin than during the warm season. The overall weaker flow leads to a shorter period of dynamical adjustment within the model.

(2) Since data from the target regions were not available, proxy locations were used to represent the target locations. The proxy locations included the network of observations that were assimilated with the forecast verification being computed at the location of the assimilated met tower in areas close to the target location. A second network of low-level (10- to $20-\mathrm{m})$ met towers was also used for verification, but observations for this dataset were only available during the second part of the cool season.

(3) The high and low sensitivity locations were selected using the ESA results performed for the warm season because no cool season sensitivity study had been performed for the region.

\subsubsection{Verification Using Older Met Towers}

The results from the met tower closest to Stateline, the Vansycle met tower, are presented here and used as a proxy for the Stateline location. Observations from the Vansycle met tower were available at three separate levels but the level closest to hub height (62 meters) is presented in this report.

The control run forecast MAE of the 62-m wind speed at Vansycle for the cool season period (blue line, Figure 7) showed a similar pattern but with different magnitudes from that of the warm season results at the Stateline location. The MAE decreased for the first hour from 2.7 to $2.1 \mathrm{~ms}^{-1}$ during the 0.5 - to one-hour time frame. As with the warm season control run, the decrease in MAE during the first hour is likely related to imbalances in the initial state and resulting spin-up period. After the first hour of the control run, the MAE increased and decreased between an MAE range of about $2.1 \mathrm{~ms}^{-1}$ and $2.7 \mathrm{~ms}^{-1}$.

The forecasts that assimilated all available met tower data (orange-red line, Figure 7) showed a significant reduction in the initial error, with MAE of about $1.4 \mathrm{~ms}^{-1}$. Because the met tower data assimilated in this run included the Vansycle observation, there was a significant drop in MAE and bias (Figure 8) when compared to the control run. This behavior is common when verification is performed at the site of observation assimilation. Also, for the all met tower run, the impact of assimilating observations was to decrease the forecast MAE and bias (Figures 7 and 8) compared to the control run during the first 3 hours. After this period, the impact of the 
observations in the model became more diffuse and the difference in MAE compared to the control run decreased.

The all-met tower cool season bias (Figure 8) is somewhat different when compared to the warm season (Figure 6). For the warm season, the all-met tower biases were initially positive and 1.0 $\mathrm{ms}^{-1}$ closer to zero than the control. The all-met tower and control warm season bias converged at about the 2-hour point and remained approximately the same for the remainder of the forecast period. In the cool season, the all-met tower bias starts negative $(-0.5)$ and is about $1.5 \mathrm{~ms}^{-1}$ closer to zero than the control. The cool season bias values again converge at about the 2-hour point. After the 2-hour point, the all met tower bias stays mostly negative between -0.5 and 0 $\mathrm{ms}^{-1}$ while the control bias oscillates around the zero line, staying between -0.5 and $+0.4 \mathrm{~ms}^{-1}$.

VNM COOL SEASON MAE

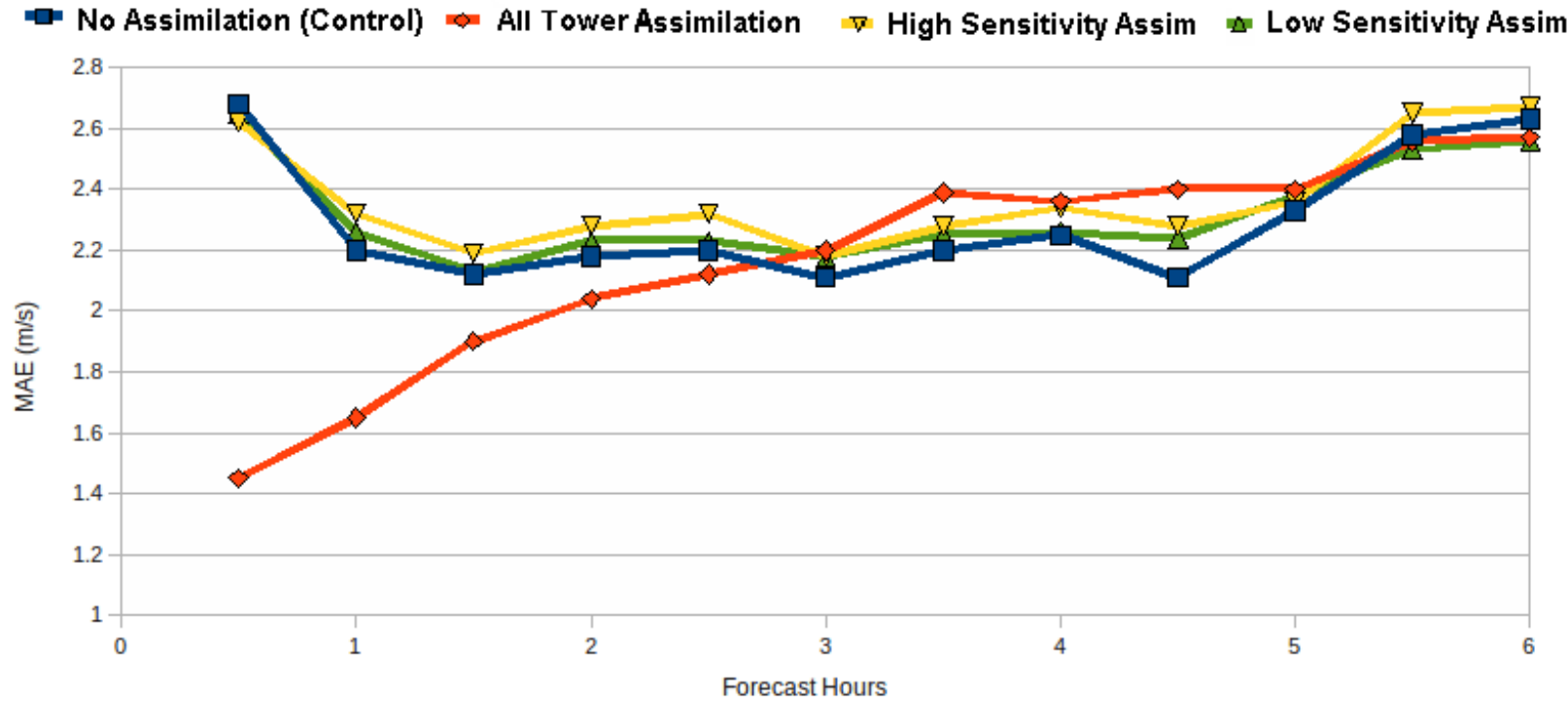

Figure 7. Same as Figure 4 except for 62-m wind speed $\left(\mathrm{ms}^{-1}\right)$ for the VNM (Vansycle) met tower for the cool season (1 January - 20 February 2010).

The cool season MAE and bias analysis (Figures 7 and 8) for both the high and low sensitivity experiments, show an MAE similar to the control run. This result indicates that, for this particular location and period, there was no significant forecast impact due to assimilating met tower observations taken at estimated high and low sensitivity areas. The only discernable difference is a slight improvement in forecast bias for the first three hours from the high sensitivity run as compared to the low sensitivity run. 


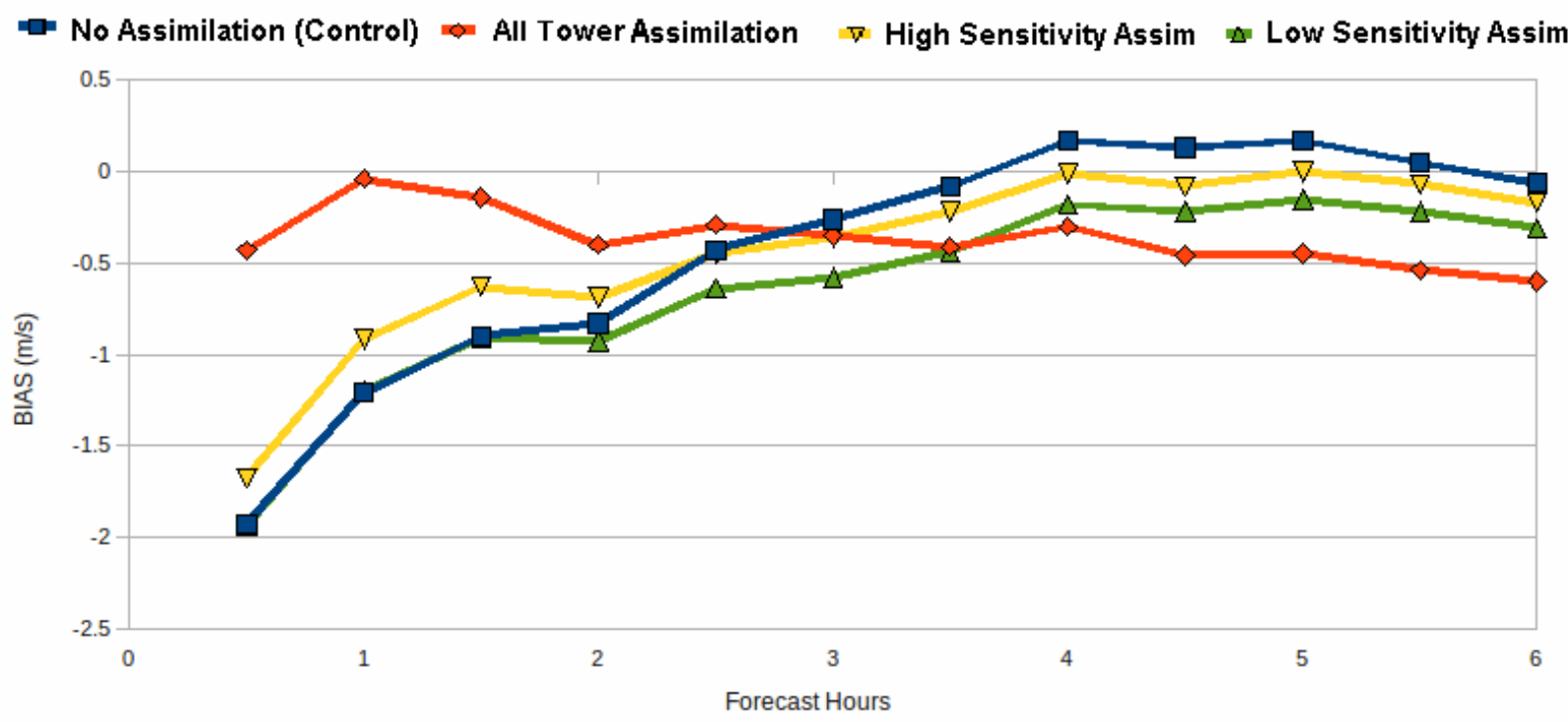

Figure 8. Same as Figure 6 except for 62-m wind speed $\left(\mathrm{ms}^{-1}\right)$ for the VNM (Vansycle) met tower for the cool season (1 January - 20 February 2010).

\subsubsection{New Met Tower Verification (February Only)}

A second network of observations was used for verification purposes as proxy sites for the wind plant locations. These sites are close to the target locations and independent from the assimilated observation. Since data from these sites were not available until February, the results only pertain to the last 20 days of the cool season period.

The 10-m level of the Hood River met tower forecast verification of MAE and bias show an improvement from the assimilation of data when compared to that of the control run (Figures 9 and 10). Unlike results presented with the assimilated tower data, the Hood River site initially shows a higher MAE and bias from 0.5 to $1 \mathrm{~h}$ compared with the control run. After a 2- to 3-hour period of adjustment in the model, the assimilation run MAE outperforms the control run by an average of about $0.4 \mathrm{~ms}^{-1}$ especially from forecast hour 5 to 15 . Although the $20 \mathrm{-m}$ Hood River MAE and bias showed a similar result between the control and assimilation run, the magnitude of this difference is much less (not shown). These results would indicate that the assimilation of the entire network of met towers provides an improvement in forecast performance for forecasts beyond 3 hours. 
HRM COOL SEASON MAE

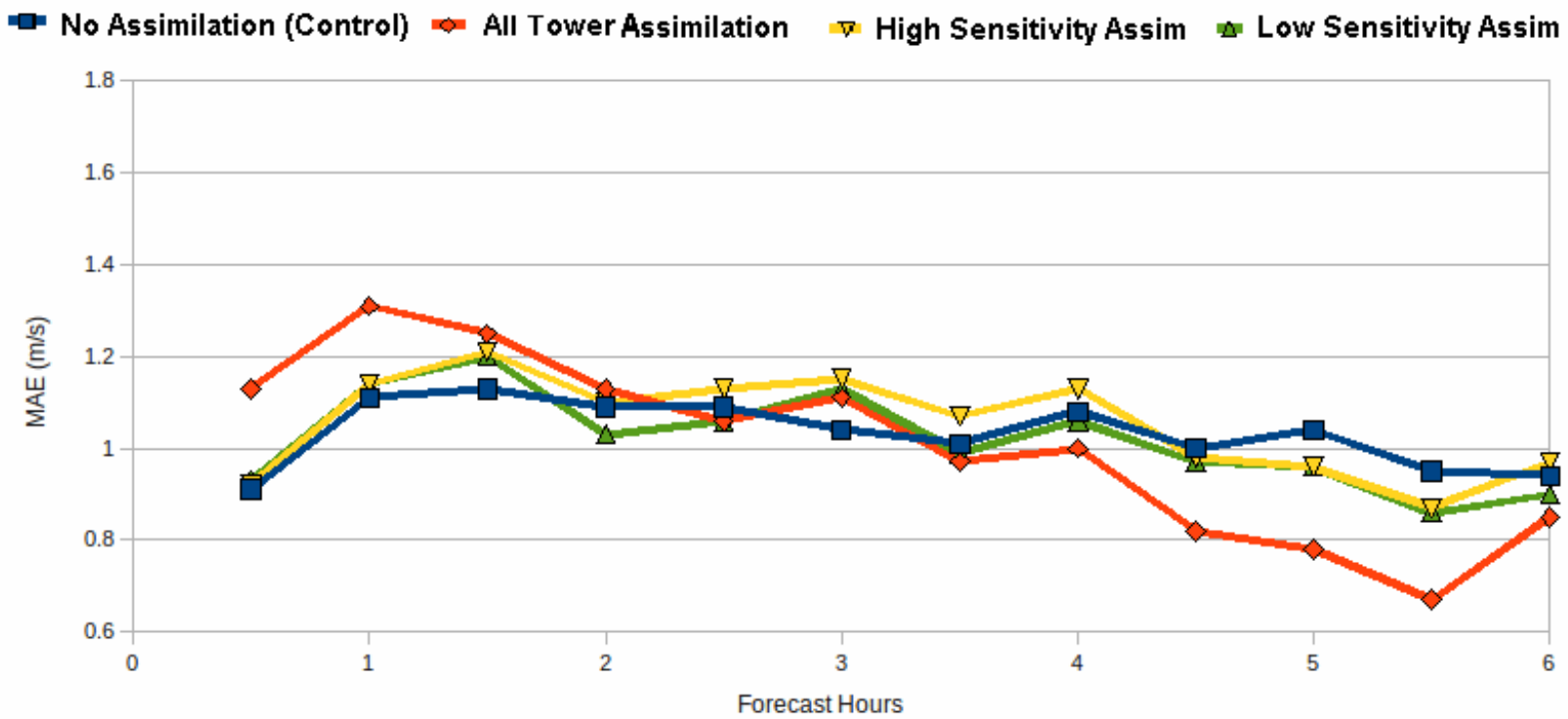

Figure 9. Same as Figure 4 except for 10-m wind speed $\left(\mathrm{ms}^{-1}\right)$ for the HRM (Hood River) met tower for the cool season (1 January - 20 February 2010).

\section{HRM COOL SEASON BIAS}

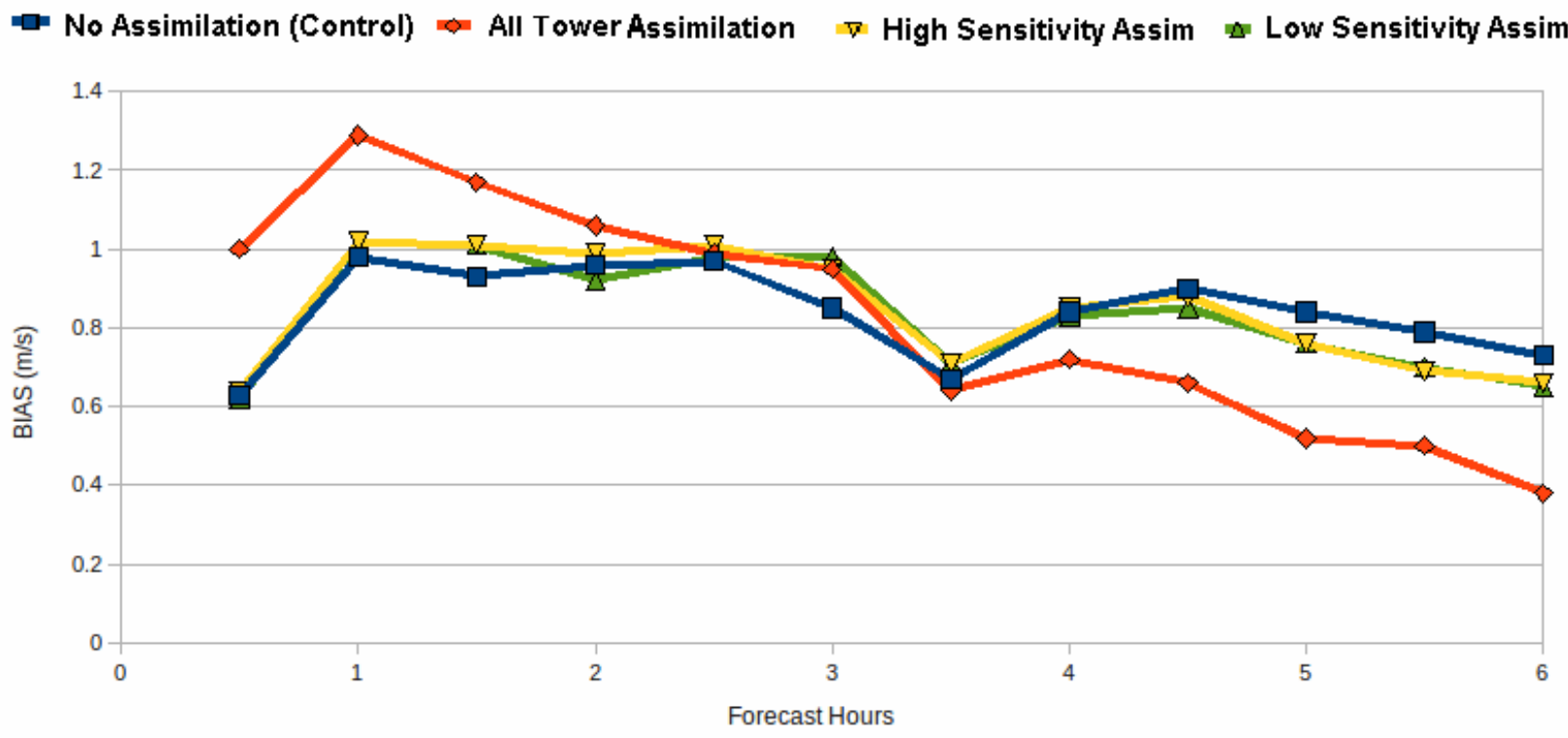

Figure 10. Same as Figure 9 except for bias.

Unlike the Hood River results, the Wasco met tower MAE results (Figure 11) showed an improvement within the first 2 to 3 hours of the forecast when compared to the control run and a decrease in forecast performance from 6 to 12 hours. The improvement initially is on the order of $0.5 \mathrm{~ms}^{-1}$ and may be due to the proximity of observation locations to the Wasco met tower location, similar to the Vansycle results. Also, similar to the Vansycle met tower cool season 
results, there is little indication of improvement obtained from the assimilation of met tower data from estimated high as compared to low sensitivity areas for either the Hood River or Wasco verifications sites.

WOM COOL SEASON MAE

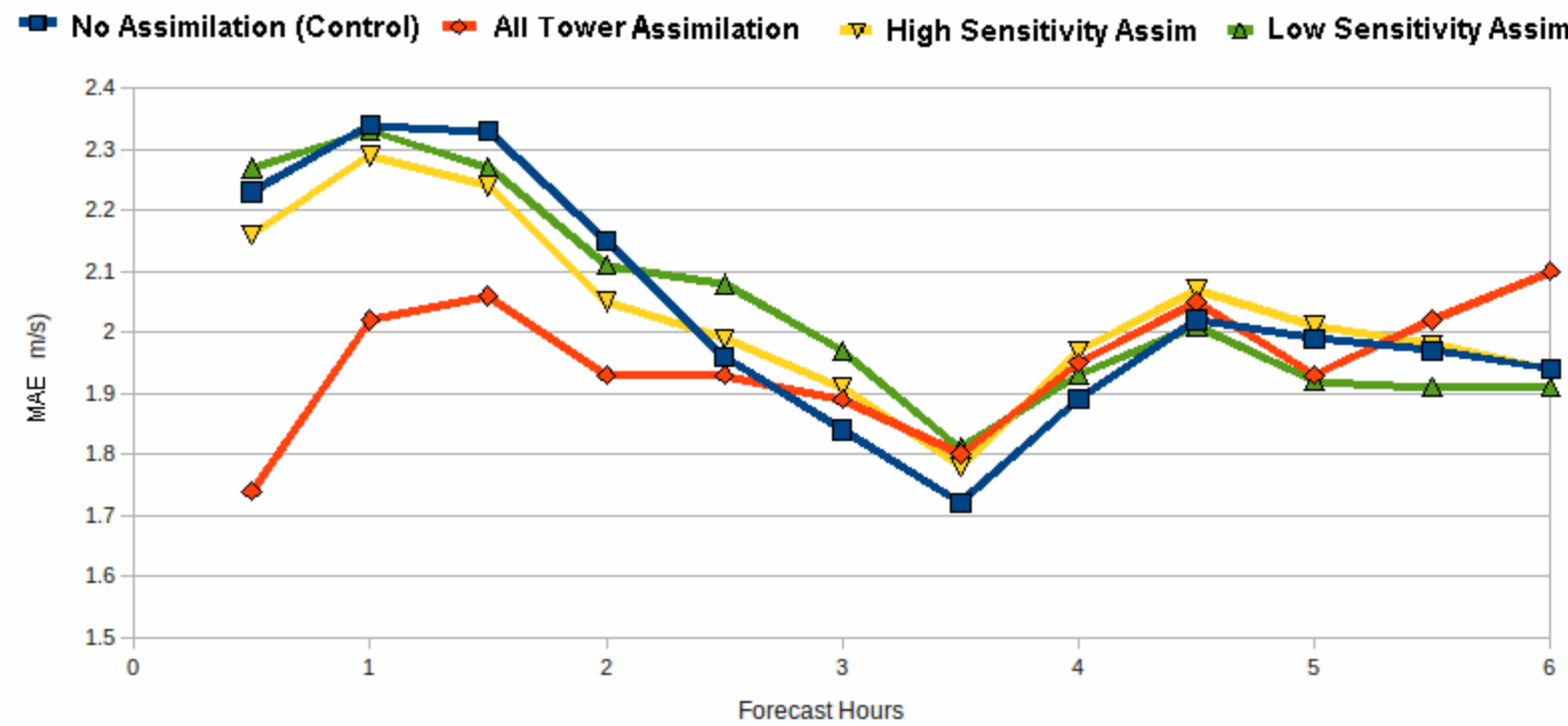

Figure 11. Same as Figure 9 except for $10-\mathrm{m}$ wind speed $\left(\mathrm{ms}^{-1}\right)$ for the WOM (Wasco) met tower for the cool season (1 January - 20 February 2010).

\subsubsection{Cool Season Summary}

The cool season results are somewhat mixed from location to location. However, it can be inferred that assimilating met tower observations does have a positive impact on forecast performance. This result was seen as a direct forecast improvement before 3 hours at the Vansycle and Wasco sites and after the first 3 hours at the Hood River site. The overall results of the study indicate that the initial model state and forecast hours not impacted by spin up are improved when observed tower data are assimilated. However, due to the lack of observations during the cool season at the target site, it can only be inferred that these results are relevant to the actual target locations.

Even though there are differences between the cool and warm season results, the cool season results are consistent with the warm season conclusions: (1) adding met tower observations significantly improved the initial state of the and (2) imbalances are introduced in to the model causing an increase in error during the spin-up time.

\subsection{Additional Runs to Address Dynamic Imbalance from Assimilation}

In order to understand better the impact of assimilating met tower observations on the forecasts, four additional experiments were performed for the warm season. The additional warm season experiments all involved modifications to the assimilation procedure for runs that used all met tower data as follows: 


\section{1) Divergence constraint}

2) Modified covariance

3) IAU

4) Assimilation using the Bratseth scheme within ADAS

All of these additional runs were chosen to address the hypothesized dynamic imbalance created from assimilating observations into the initial model state.

The results for this section will focus on the warm season Stateline results because the location and period is deemed to be most representative of sensitivity values created by the ESA technique. As with the original all met tower assimilation run, the dynamic imbalance in the initial state impacts the forecast most during the first three hours.

The imbalance seems to have the largest negative impact on the divergence, IAU, and ADAS runs which all have MAE values above $2.5 \mathrm{~ms}^{-1}$ during the first 4 hours of the forecast (Figure 12 and 13). The IAU run had the worst performance in terms of MAE which may be due to the fact that observations gradually assimilated into the model may increase the time needed to dissipate the imbalances. However, IAU has shown promising results for other regions and applications with higher density data networks, especially when having the model adapt to the analysis increment prior to model initialization.

Other techniques, such as the divergence constraint, may have increased the imbalance since the model may not be able to correctly represent the terrain flows partially resolved by the assimilated data. Therefore an approximation of the mass continuity constraint on the 4-km grid spacing of the assimilation system may have not been appropriate for the region. The Bratseth (ADAS) assimilation system had the lowest MAE near the time of initialization, but the instabilities with the initial state dissipated slower, causing an increase in the forecast MAE in the first 2 to 5 hours of the forecast.

It is significant to note that forecasts which assimilated data from all the met tower observations had the overall lowest MAE for the first 3 hours in the modified covariance experiment. Most importantly, the modified covariance run had the second lowest 30-minute forecast MAE which was a little higher than the ADAS run, but produced a forecast error significantly less than that of the original all-met tower assimilation run. This important result demonstrates that forecast performance is directly related (and sensitive) the size of the spatial area that the observations impact within the initial model state.

Additional investigations using different covariance structures may provide further insight on how to improve both the location of met tower observations sites based on the ESA technique and the impact of data assimilation. The ESA employs an anisotropic analysis increment, similar to the pseudo-anisotropic recursive filters in the modified correlation experiment. The results of the modified covariance experiment indicate that the ARPS 3DVAR data assimilation system used in the experiment cannot estimate with the same detail the areas that can be impacted by the observations as the ESA technique recently developed by Zack et al. (2010a, b, and c). The 
lower forecast MAE of the modified correlation runs suggests that a technique similar to the ESA technique will be needed to validate the sensitivity structure produced by the by Zack et al. (2010a, b, and c) ESA technique.

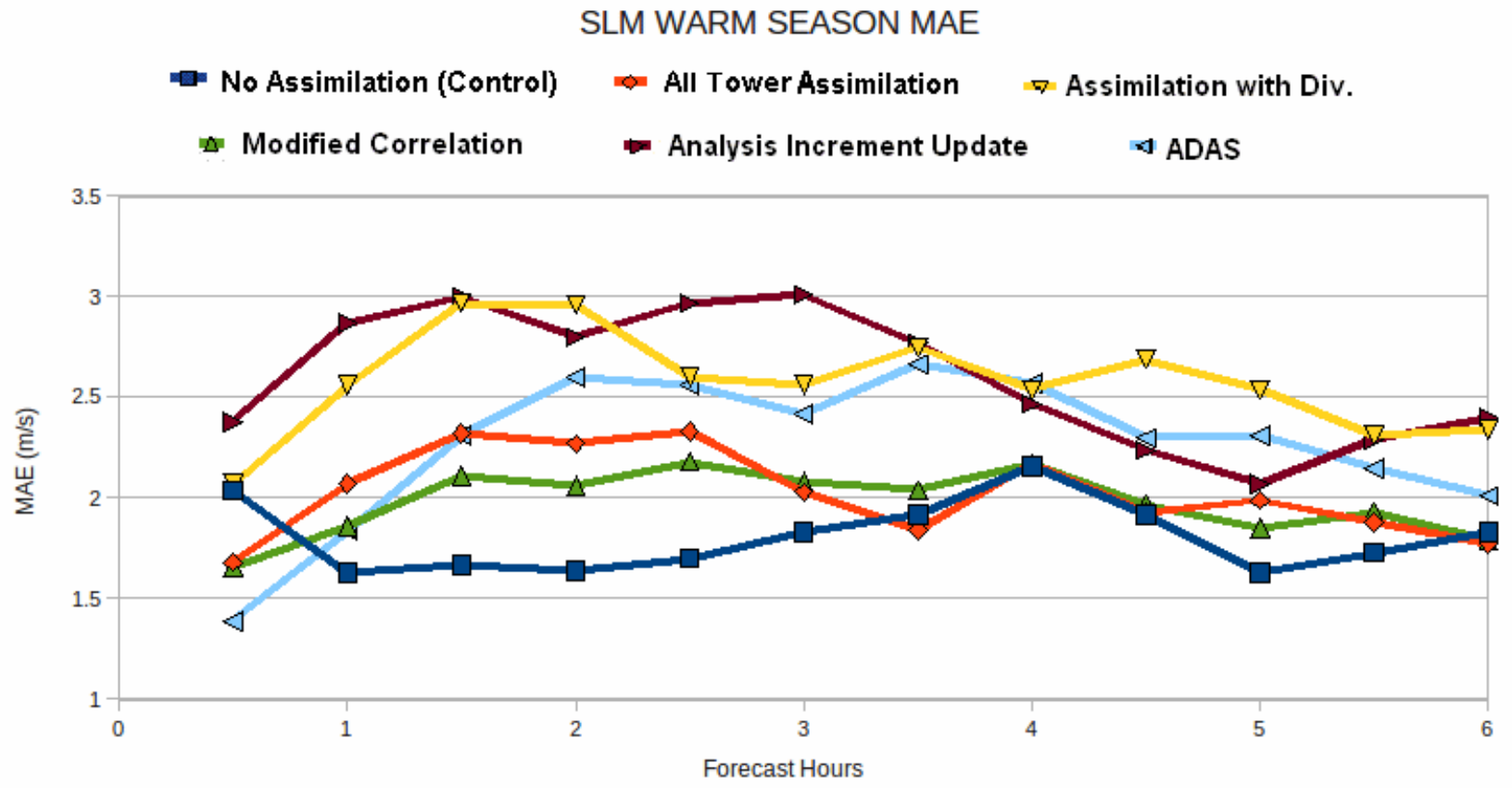

Figure 12. Mean absolute error (MAE) as a function of look-ahead time for twice per day (0000 and 1200 UTC initialization times) NWP forecasts of 80-m wind speed $\left(\mathrm{ms}^{-1}\right)$ for the SLM (Stateline) wind farm for the warm season (1 May - 20 June 2007) for the control run without met tower data assimilation (dark blue line), the all six Bonneville Power Administration (BPA) meteorological tower data assimilation run (red-orange line), assimilation with the divergent constraint (yellow line), the assimilation with a modified correlation function (green line), the assimilation using IAU (brown line), and the assimilation using ADAS (light blue line) using observations from the six BPA meteorological towers. 


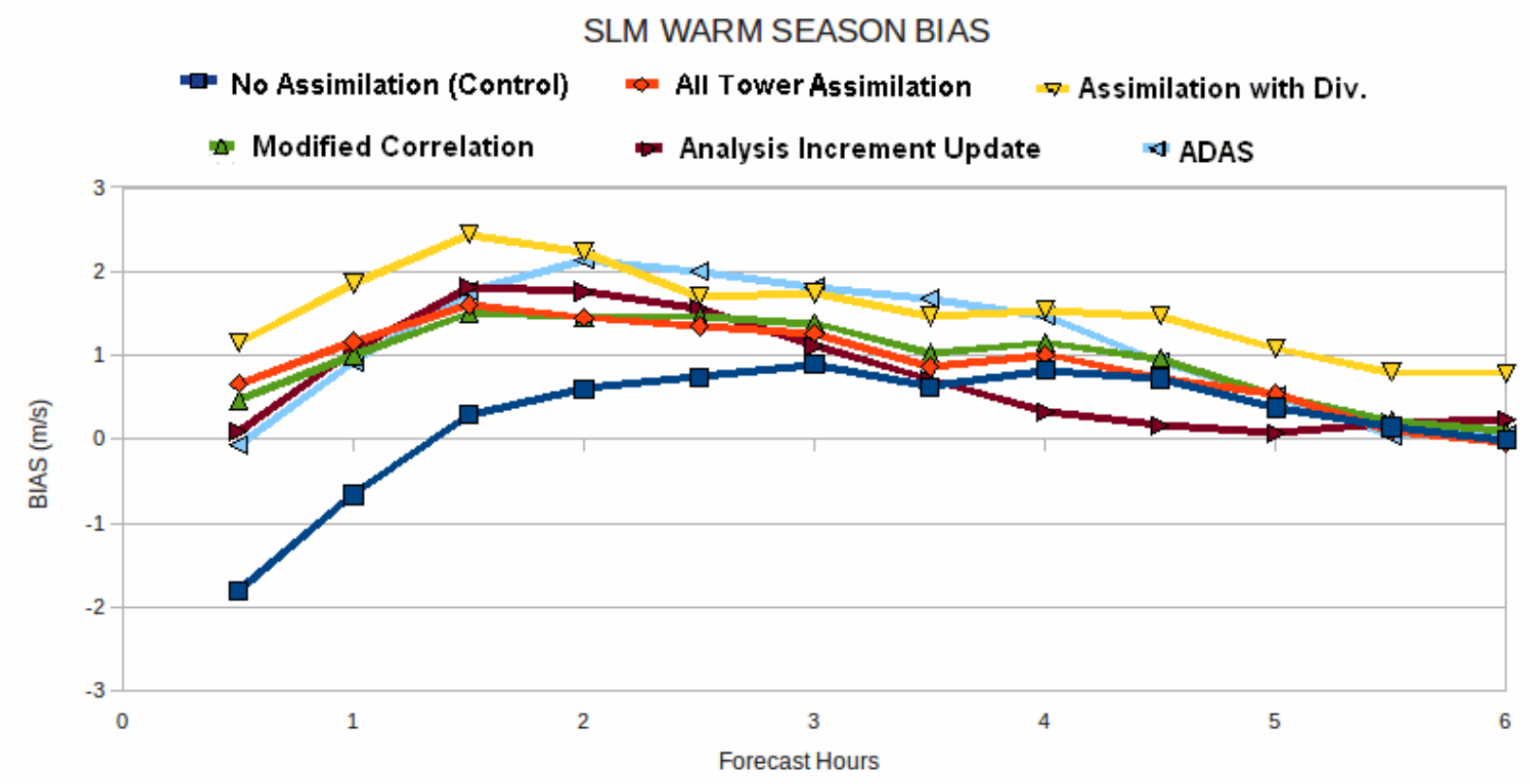

Figure 13. Bias as a function of look-ahead time for twice per day (0000 and 1200 UTC initialization times) NWP forecasts of 80-m wind speed $\left(\mathrm{ms}^{-1}\right)$ for the SLM (Stateline) wind farm for the warm season (1 May - 20 June 2007) for the control run without met tower data assimilation (dark blue line), the all six Bonneville Power Administration (BPA) meteorological tower data assimilation run (red-orange line), assimilation with the divergent constraint (yellow line), the assimilation with a modified correlation function (green line), the assimilation using IAU (brown line), and the assimilation using ADAS (light blue line) using observations from the six BPA meteorological towers.

\section{Summary}

Three sets of data denial and assimilation experiments were performed using historical data in order to validate the ESA approach for the Mid-Colombia Basin region. The impact of met tower observations was examined for locations for which forecasts were predicted to be sensitive to the atmospheric state by the ESA-MOOA method developed by Zack et al. (2010a, b, and c). The objective of the data denial and assimilation experiments was to determine if the $80-\mathrm{m}$ wind forecasts for three target locations were more sensitive to actual met tower observations in highly sensitive areas versus areas of low sensitivity with the inference being that meteorological observations within the highly sensitive areas would lead to better forecast performance.

The first set of experiments was performed for the warm season, testing the impact of assimilating data at high and low sensitive locations compared with assimilating all available met tower data regardless of location. The results indicated that adding met tower observations significantly improved the initial state of the atmosphere at the target locations, but the experiments also indicated that imbalances were introduced from data assimilation causing an increase in error during the first 2 to 3 hours of the forecast.

The second set of experiments was performed for the cool season using the same type of 
sensitivity experiments as done for the warm season. The analysis of the cool season results was hindered by the fact that met tower observations for the target locations were not available for this time period so proxy sites were used for verification.

The results from the cool season experiments differed somewhat from location to location, making it difficult to draw a general conclusion. Part of the reason for this difference was due to the fact that off-site proxy met towers had to be used for verification, instead of on-site observations. Even with the difficulties caused by not having target location met towers, it is reasonable to infer that assimilating met tower observations does have a direct impact on the forecasts by improving the initial model state and also forecast performance for the first 3 hours.

The third set of four warm season experiments was designed to learn more about the impact of the data assimilation scheme used to assimilate the met tower observations into the model's initial state. These experiments all involved modifications of the warm season experiment that assimilated all available met tower data.

The divergence constraint, IAU and ADAS experiments did not improve the forecasts. However, the additional experiment using a different covariance structure provided further insight into how to construct a real-time data assimilation system in order to realize the full benefits from observations in highly sensitive locations as predicted by the ESA technique.

The results from the modified covariance experiment indicate that the data assimilation system used in the experiment cannot properly estimate the spatial background covariance with the same detail as ESA. The lower forecast MAE of the modified covariance runs suggests there is a direct relationship between how the assimilation system determines the impact that an observation will have on the initial field and the forecast performance through better estimates in spatial covariance structure. Therefore, a technique that can more accurately assess the background covariance structure similar to the ESA technique, but that is more computationally efficient for real-time forecasting applications, will be needed to validate the sensitivity structure produced.

The overall results of the study indicate that the initial model state and the first forecast hour are improved when observed tower data are assimilated. For the warm season runs this impact was most pronounced closer to the initialization time, while for the cool season the improvement in the forecast was visible in the first 0 - 3 hours depending on the proxy verification location. This indicates that the forecasted atmospheric flow is highly uncorrelated with the impact of observations from one location to another location. After the third hour, the impact of the assimilated observations is minimal on the forecasts. However, a slight improvement in the forecasts with all of the met towers assimilated can be seen as far out as hour 16 in some of the forecasts. Due to the lack of observations during the cool season at the target site, it can only be implied that results presented here are relevant to the actual target locations. Results also indicate that the impact of observations were sensitive to seasonal flow, observation location, and the data assimilation scheme.

Even though there are differences between the cool and warm season results, the cool season results are consistent with the warm season conclusions: (1) adding met tower observations significantly improved the values of near surface wind speed in the initial model state of the 
atmosphere at the target locations and (2) imbalances were introduced into the model causing an increase in error during the spin-up time.

The lower forecast MAE of the modified covariance runs suggests that a technique which can better estimate background error covariance structures similar to the ESA technique will be needed to validate the sensitivity structure produced. However, the technique will need to be computationally efficient enough for real-time applications. Computationally efficient techniques, such as a hybrid-3DVAR assimilation method, that can address the need for better estimates of background error covariance structures are under development for future use. The hybrid method estimates the background error covariance by using a smaller and lower resolution ensemble that is similar to the ESA technique but requires less computational resources. This technique links the spread from the ensemble to the covariance structure of a single high-resolution 3DVAR assimilation system as described by Wang et al. (2008a, b).

In addition, bias correction techniques such as the Mass et al. (2006) method should be examined for future applications where model and assimilation biases are noticeably present. Bias correction techniques are computationally efficient and only require a simple bias correction applied directly to the observations before assimilation. This technique can be used independent of the assimilation method or numerical model used. It is particularly valuable in regions where a numerical bias is prominent as in the experiments for the Mid-Columbia River Basin. Therefore, the new hybrid assimilation technique coupled with an observational bias correction method offers the potential for short-term forecast improvement in future research projects.

\section{Acknowledgements}

This work performed under the auspices of the U.S. Department of Energy by Lawrence Livermore National Laboratory under Contract DEAC52-07NA27344. The work of the authors from AWS Truepower was performed under subcontract B584259 from Lawrence Livermore National Laboratory.

\section{References}

Ancell, B. and G. J. Hakim, 2007: Comparing adjoint- and ensemble-sensitivity analysis with applications to observation targeting. Mon. Wea. Rev., 135, 4117-4134.

Bloom, S.C., L.L. Takacs, A.M. da Silva, and D. Ledvina, 1996: Data assimilation using incremental analysis updates. Mon. Wea. Rev., 124, 1256-1271.

Bratseth, A.M., 1986: Statistical interpolation by means of successive corrections. Tellus, 38A, 439-447.

Brewster, K., 1996: Application of a Bratseth analysis scheme including Doppler radar data. Preprints, 15th Conf. on Wea. Analysis and Forecasting, 19-23 August, Amer. Meteor. Soc., Norfolk, VA, 92-95.

Evensen, G., 2007: Data assimilation: The ensemble Kalman filter. Springer, Berlin, 307 pp.

Gao, J., M. Xue, A. Shapiro, and K. K. Droegemeier, 1999: A variational method for the analysis 
of three-dimensional wind fields from two Doppler radars. Mon. Wea. Rev., 127, $2128-$ 2142.

Gao, J., M. Xue, K. Brewster, and K. K. Droegemeier, 2004: A three dimensional variational data analysis method with recursive filter for Doppler radars. J. Atmos. Oceanic Technol., 21,457-469.

Houtekamer P. and H. L. Mitchell, 1998: Data assimilation using an ensemble Kalman filter technique, Mon. Wea. Rev., 126. 796-811.

Hu, M., M. Xue, J.-D. Gao and K. Brewster, 2006: 3DVAR and cloud analysis with WSR-88D Level-II Data for the prediction of the Fort Worth, Texas, tornadic thunderstorms. Mon. Wea. Rev., 134, 699-721.

Janjić, T., and S. E. Cohn, 2006: Treatment of observation error due to unresolved scales in atmospheric data assimilation. Mon. Wea. Rev., 134, 2900-2915.

Lin, Y.-L., R. D. Farley, and H. D. Orville, 1983: Bulk parameterization of the snow field in a cloud model. J. Appl. Meteor., 22, 1065-1092.

Mass, Clifford F., Jeffrey Baars, Garrett Wedam, Eric Grimit, Richard Steed, 2008: Removal of systematic model bias on a model grid. Wea. Forecasting, 23, 438-459.

Sharp, J. and C. F. Mass, 2002: Columbia Gorge gap flow: Insights from observational analysis and ultra-high resolution simulation. Bull. Amer. Meteor. Soc., 83, 1757-1762.

Torn, R. D., and G. J. Hakim, 2008: Ensemble-based sensitivity analysis. Mon. Wea. Rev., 136, 663-677.

Wang, X., D. M. Barker, C. Snyder, and T. M. Hamill, 2008: A Hybrid ETKF-3DVAR Data Assimilation Scheme for the WRF Model. Part I: Observing System Simulation Experiment. Mon. Wea. Rev., 136, 5116-5131.

Wang, X., D. M. Barker, C. Snyder, and T. M. Hamill, 2008: A Hybrid ETKF-3DVAR Data Assimilation Scheme for the WRF Model. Part II: Real Observation Experiments. Mon. Wea. Rev., 136, 5132-5147.

Xue, M., K. K. Droegemeier, and V. Wong, 2000: The Advanced Regional Prediction System (ARPS) - A multiscale nonhydrostatic atmospheric simulation and prediction tool. Part I: Model dynamics and verification. Meteor. Atmos. Physics., 75, 161-193.

Xue, M., K. K. Droegemeier, and V. Wong, A. Shapiro, K. Brewster, F. Carr, D. Weber, Y. Liu, and D.-H. Wang, 2001: The Advanced Regional Prediction System (ARPS) - A multiscale nonhydrostatic atmospheric simulation and prediction tool. Part II: Model physics and applications. Meteor. Atmos. Phys., 76, 143-165.

Xue, M., D.-H. Wang, J.-D. Gao, K. Brewster, and K. K. Droegemeier, 2003: The Advanced Regional Prediction System (ARPS), storm-scale numerical weather prediction and data assimilation. Meteor. Atmos. Phys., 82, 139-170.

Zack, J., E. Natenberg, S. Young, J. Manobianco, and C. Kamath, 2010a: Application of ensemble sensitivity analysis to observation targeting for short-term wind speed forecasting. Technical Report LLNL-TR-424442, 32 pp., Lawrence Livermore National 
Laboratory, Livermore, CA.

Zack, J., E. Natenberg, S. Young, G. Van Knowe, K. Waight, J. Manobianco, and C. Kamath, 2010b: Application of ensemble sensitivity analysis to observation targeting for short term wind speed forecasting in the Washington - Oregon Region. Technical Report LLNL-TR-458086, 65 pp., Lawrence Livermore National Laboratory, Livermore, CA.

Zack, J., E. Natenberg, S. Young, G. Van Knowe, K. Waight, J. Manobianco, and C. Kamath, 2010c: Application of ensemble sensitivity analysis to observation targeting for shortterm wind speed forecasting in the Tehachapi Region winter season. Technical Report LLNL-TR-460956, 57 pp., Lawrence Livermore National Laboratory, Livermore, CA. 